\title{
The CCL2 Chemokine Promotes Early Seeding of the Latent HIV Reservoir
}

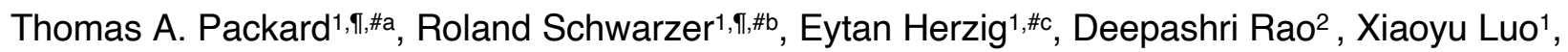
Johanne H. Egedal1,\#d, Feng Hsiao1, Marek Widera ${ }^{3}$, Judd F. Hultquist ${ }^{1,4, \# e, ~ Z a c h a r y ~ W . ~}$ Grimmett $^{1}$, Ronald J. Messer ${ }^{2}$, Nevan J. Krogann ${ }^{1,4}$, Steven G. Deeks ${ }^{5}$, Nadia R. Roan ${ }^{1,6}$, Ulf Dittmer $^{3}$, Kim J. Hasenkrug ${ }^{2}$, and Warner C. Greene 1,5,7,*

1 J. David Gladstone Institutes, San Francisco, CA 94158 USA

2 Laboratory of Persistent Viral Diseases, Rocky Mountain Laboratories, National Institute of Allergy and Infectious Diseases, National Institutes of Health, Hamilton, MT 59840 USA

3 Institute for Translational HIV Research, University Hospital Essen, University of Duisburg-Essen, 45122, Germany

4 Quantitative Biosciences Institute (QBI) and Department of Cellular and Molecular Pharmacology, University of California San Francisco, San Francisco, CA 94158

5 Department of Medicine, University of California San Francisco, San Francisco, CA 94110, USA

6 Department of Urology, University of California San Francisco, San Francisco, CA 94158, USA

7 Department of Microbiology \& Immunology, University of California San Francisco, San Francisco, CA 94158, USA

\#a Current address: Shape Therapeutics, Seattle, WA 98109, USA

\#b Current address: Institute for Translational HIV Research, University Hospital Essen, University of Duisburg-Essen, 45122, Germany

\#c Current address: Chimera Bioengineering, San Francisco, CA 94080, USA

\#d Current address: Department of Biomedicine, Aarhus University, Aarhus, Denmark

\#e Current address: Department of Medicine, Northwestern University, Evanston, IL 60208, USA

I These authors contributed equally to this work.

* Corresponding author: warner.greene@gladstone.ucsf.edu

\section{ABSTRACT}

1
HIV infects long-lived CD4 memory T cells establishing a latent viral reservoir that necessitates lifelong anti-retroviral therapy (ART). How this reservoir is formed so swiftly remains unknown. We now show the innate inflammatory response to HIV infection results in CCL2 chemokine release, which can drive recruitment of cells expressing the CCR2 receptor including a subset of central memory CD4 T cells. Supporting a role for the CCL2/CCR2 axis in rapid reservoir formation, we find 1) treatment of humanized mice with anti-CCL2 antibodies during HIV infection 
decreases reservoir seeding and 2) CCR2/5+ cells from the blood of HIV-infected individuals on

9 long term ART contain significantly more provirus than CCR2/5-negative memory or naïve cells.

10 Together, these studies support a model where the host's innate inflammatory CCL2 response to

11 HIV infection recruits CCR2/5+ central memory CD4 T cells to zones of virus-associated

12 inflammation likely contributing to rapid formation of the latent HIV reservoir.

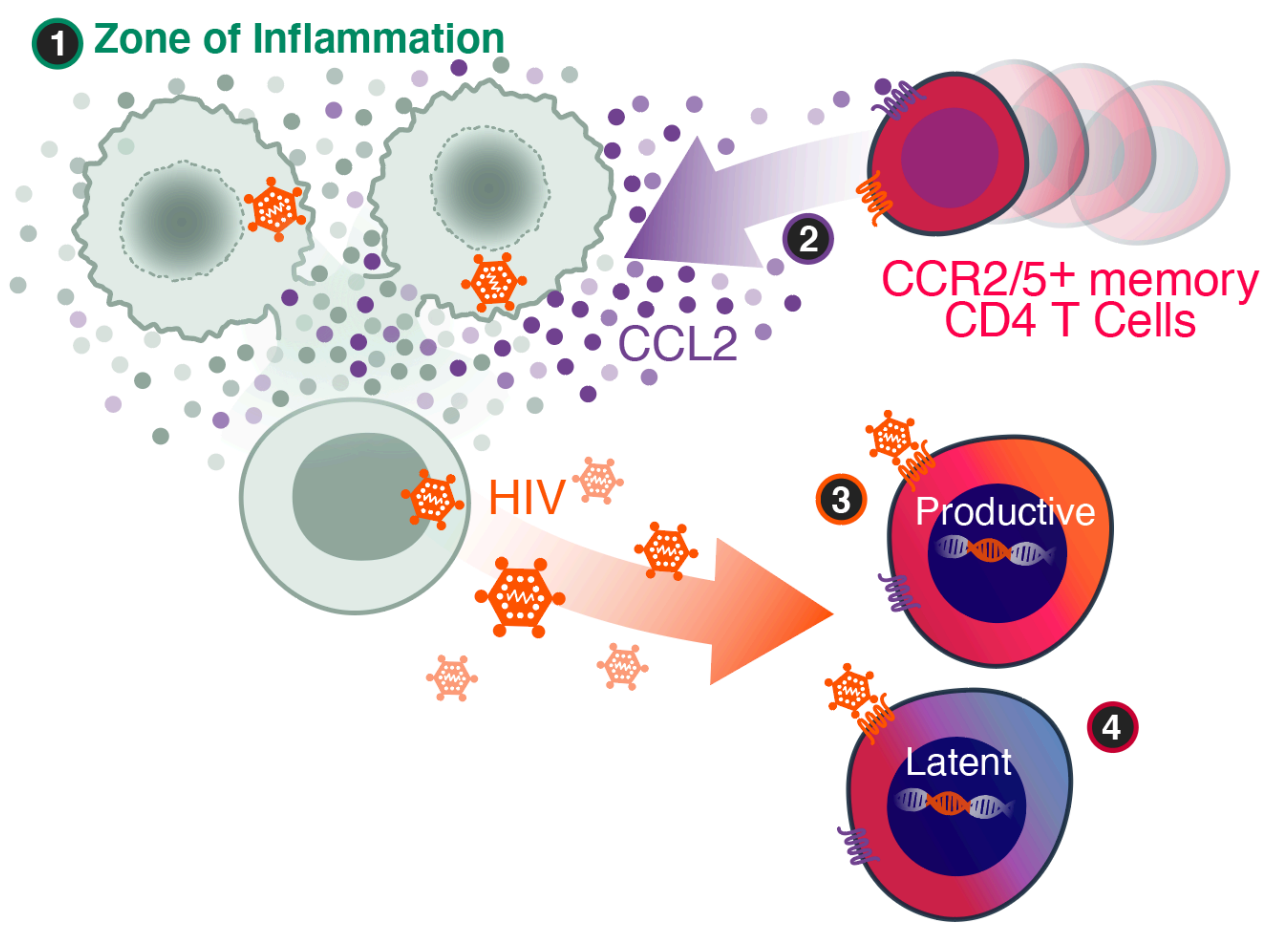

\section{GRAPHICAL ABSTRACT}

Why is the latent HIV reservoir established so early following infection? An innate immune

16 response occurs during acute infection that establishes a "zone of inflammation" (step 1). The

17 CCL2 chemokine is produced in part through IFI16 sensing of HIV DNA in abortively infected cells. CCL2 promotes rapid recruitment of CCR2/5+ memory CD4 T cells (step 2). Many of these

19 cells become productively infected (step 3) and a fraction become latently infected (step 4). Thus,

20 HIV hijacks the host inflammatory response to rapidly establish the latent reservoir. In support of 
21 this model, we find HIV reservoir reduction in humanized mice treated with anti-CCL2 antibodies

22 during early infection. Further, we find that CCR2/5+ CD4 T cells harbor a substantial fraction of

23 detectable proviruses in the blood of HIV-infected individuals on long-term suppressive ART.

\section{INTRODUCTION}

26 The latent HIV reservoir is comprised of infectious proviruses predominantly within memory CD4

27 T cells. These cells are not effectively depleted by antiretroviral therapy (ART), making lifelong

28 treatment a requirement to prevent disease progression. Targeted elimination or control of the

29 latent HIV reservoir is critical for achieving an HIV cure. In rhesus macaques, a stable SIV

30 reservoir is established within 3 days or less following infection ${ }^{1}$. Likewise, the HIV reservoir is

31 rapidly seeded in humans. Administration of ART immediately after detection of HIV RNA in

32 plasma prior to detection of p24gag or seroconversion (Fiebig stage I) in closely monitored, high

33 risk individuals, fails to prevent viral rebound during a subsequent analytical treatment interruption

34 2. Similarly, initiation of ART approximately 10 days after infection (very early Fiebig stage I) does

35 not prevent viral rebound following ART withdrawal ${ }^{3}$. These findings highlight rapid seeding of

36 the HIV reservoir.

38 The HIV reservoir is long-lived and self-renewing, as are CD4 central memory T cells. Indeed,

39 many latent proviruses are found within central memory T cells, suggesting they form an important

40 component of the viral reservoir ${ }^{4-7}$. However, HIV preferentially infects effector CD4 T cells ${ }^{8-10}$.

41 Effector T cells are terminally differentiated and short-lived. Due to their short lifespan, these cells

42 likely do not contribute to maintenance of the long-lived latent reservoir. How HIV quickly

43 establishes infection in central memory T cells is unknown. HIV may infect central memory

44 precursors, such as stem cell-like memory cells $\left(\mathrm{T}_{\mathrm{SCM}}\right)^{11}$, although these cells are quite rare.

45 Alternatively, HIV could directly infect central memory T cells. 
A potential mechanism for the recruitment of memory cells to the site of infection is via

47 chemoattraction. Acute infection by HIV drives the production of multiple cytokines. Prominent

48 among these is the C-C motif ligand 2 chemokine (CCL2/MCP-1) ${ }^{12-14}$. CCL2 is one of the first

49 cytokines detected during the acute phase of HIV infection, preceding peak viremia and

50 correlating with viral load ${ }^{12,13,15}$. CCL2 is also involved in the development of the HIV-associated

51 neurocognitive disorder (HAND), attracting cells to cross the blood brain barrier ${ }^{16-20}$. CCL2's swift

52 upregulation during acute infection raises the possibility that this chemokine might be involved in

53 the early recruitment of cells involved in latent reservoir formation.

55 During the course of HIV infection, permissive CD4 T cells can undergo productive infection.

56 Additionally, a large proportion of nonpermissive CD4 T cells in lymphoid tissues are susceptible

57 to abortive infection ${ }^{21-23}$. These abortively infected CD4 T cells ultimately die by inflammatory

58 pyroptosis ${ }^{24,25}$. This response is driven by detection of HIV reverse transcripts by the innate DNA

59 sensor, interferon-inducible protein 16 (IFI16) ${ }^{26}$. In addition to triggering pyroptosis, IFI16 also

60 activates stimulator of interferon genes (STING). STING then stimulates type 1 interferon (IFN1)

61 via IRF3 phosphorylation ${ }^{27}$, and CCL2 production via phosphorylation of STAT6 ${ }^{28}$. We set out to

62 understand the mechanisms that underlie CCL2 production during HIV infection and to

63 characterize the types of CD4 T cells recruited by this chemokine. We describe an intriguing link

64 between innate inflammation, CCL2 production, and the recruitment of CCR2/5+ memory T cells

65 that may facilitate rapid formation of the latent HIV reservoir.

\section{RESULTS}

67 HIV triggers IFI16/STING signaling to produce CCL2 in lymphoid CD4 T cells

68 To investigate whether CCL2 is induced in lymphoid tissue-derived CD4 T cells in response to

69 HIV, we used a previously described in vitro cell overlay model ${ }^{21}$. This method allows for the 
70 rapid, synchronous infection of CD4 T cells purified from human tonsils. When measured 18 hours

71 after infection, transcription of CCL2 and IFNB1 were significantly up-regulated while CCL20, an

72 alternative STAT6-regulated chemokine, was not induced (Figure 1A, Figure 1-figure

73 supplement 1). CCL2 protein levels were also increased in the supernatant measured at 24 hours

74 after infection (Figure 1B). In prior studies, blood-derived CD4 T cells exhibited impaired innate

75 immune responses to HIV ${ }^{21-23}$. Indeed, in contrast to lymphoid tissue CD4 T cells, blood CD4 T

76 cells failed to produce CCL2 (Figure 1-figure supplement 1). Basal levels of CCL2 expression

77 were also increased in uninfected CD4 T cells from lymphoid tissue compared to blood,

78 underscoring the importance of studying tissue-derived T cells in models of HIV infection.

80 To probe which component of the viral lifecycle was required to induce CCL2 production, we

81 employed drugs acting at different steps of HIV replication. CCL2 production was reduced by

82 addition of efavirenz, a non-nucleoside reverse transcriptase inhibitor (Figure 1A), but was

83 unaffected by the integrase inhibitor raltegravir (Figure 1B). Thus, an HIV cDNA intermediate,

84 produced during reverse transcription, appears to trigger rapid CCL2 production by lymphoid CD4

85 T cells and HIV integration is not required for this response.

87 This pattern of ART inhibition and lack of response in blood-derived T cells was reminiscent of

88 the pyroptotic cell death response occurring in bystander lymphoid tissue CD4 T cells following

89 abortive HIV infection ${ }^{24,25}$. Abortive infection induces pyroptosis through IFI16 sensing of HIV

90 reverse transcripts ${ }^{26}$. Both IFI16 and the cytosolic DNA sensor cyclic GMP-AMP synthase (cGAS)

91 can activate STING ${ }^{27,29}$. In turn, STING can trigger CCL2 production via activation of TBK1 and

92 STAT6 ${ }^{28}$. To determine which DNA sensors were driving CCL2 production in lymphoid tissue

93 CD4 T cells, CRISPR-Cas9 ribonucleoproteins (Cas9RNPs), were used to knockout the IFI16,

94 STING or cGAS genes (Figure 1C). Knockout of either IFI16 or STING resulted in significantly 
95 decreased CCL2 release following HIV infection compared to non-targeted controls (Figure 1D).

96 Knocking out cGAS trended to decrease CCL2 release but did not reach statistical significance.

97 Together, these results indicated that the innate DNA sensing pathway involving IFI16 and STING

98 played an important role in the rapid synthesis and release of CCL2 by lymphoid CD4 T cells in

99 response to HIV infection.

100

101 CCR2 is expressed by a population of CCR5+ central memory cells

102 A major function of CCL2 production is to recruit cells bearing the CCL2 receptor, CCR2 ${ }^{30,31 .}$

103 CCR2 is highly expressed on monocytes and is responsible for their recruitment and infiltration

104 within sites of inflammation. Previous studies have shown that CCR2 is also expressed on a 105 unique subset of blood CCR5+ CD4 T cells displaying an effector memory phenotype ${ }^{32}$.

107 We set out to examine the phenotype of lymphoid tissue-derived CCR2/5+ cells (Figure 2, Figure 1082 -figure supplement 2). The proportion of CCR5+ cells co-expressing CCR2 was substantial:

109 approximately one third of CCR5+ CD4 T cells in the tonsil and two-thirds in the blood (Figure 110 2D). Using mass cytometry, we compared the expression of 38 markers in blood and lymphoid 111 tissue CD4 T cells (Figure 2-table supplement 1). Using tSNE dimensional reduction

112 visualization, we observed that blood- and lymphoid tissue-derived CD4 T cells sharply differed

113 (Figure 2E). CCR2/5-expressing CD4 T cells between the two compartments also differed, with

114 tonsil-derived cells having elevated expression of CD25 (IL-2Ra), CD7, ICOS, and CCR7 (Figure

$1152 \mathrm{~F}$ ). CD25 expression is upregulated on activated $\mathrm{T}$ cells but constitutively expressed on

116 regulatory T cells. However, the lymphoid CCR2/5+ CD25+ cells did not express FoxP3 so they

117 had an activated rather than regulatory phenotype (Figure 2-figure supplement 3). The high

118 expression of CCR7 in the lymphoid CCR2/5+ cells suggested that these cells were primarily 119 central memory T cells ${ }^{33}$. In contrast, CD127 and CCR6 were elevated in the blood-derived 
120 CCR2/5+ T cells indicating an effector memory phenotype. Together, these findings underscore

121 fundamental phenotypic differences in lymphoid tissue versus blood-derived CCR2/5+ T cells,

122 highlighting the enrichment of central memory in lymphoid tissues, and effector memory in the

123 circulation.

125 Comparing CCR2/5+ lymphoid tissue CD4 T cells both to their naïve counterparts and the total 126 memory population shed further light on this unique subset of cells (Figure 3A). The CCR2/5+ 127 cells expressed multiple markers of T cell activation-including surface markers previously shown

128 to be enriched in the latent HIV reservoir. In addition to CD25, these markers included PD1, OX40, 129 and HLA-DR (Figure 3B) ${ }^{34-37}$. Additionally, these CCR2/5+ cells expressed ICAM (CD54) and 130 LFA-1a (CD11a) which are important in forming the viral synapse ${ }^{38}$. Finally, they expressed a 131 pattern of surface integrins that reflected potential mucosal origins, including integrins alpha 4

132 and beta 1, as well as alpha-4-beta-7 ${ }^{39,40}$. Taken together, these analyses indicated that lymphoid 133 CCR2/5+ cells were primarily central memory CD4 T cells expressing markers associated with 134 tissue homing, and HIV permissivity-all consistent with a potential role for these cells in 135 establishing the latent HIV reservoir.

\section{CCR2/5+ cells migrate in response to CCL2 and are permissive to HIV infection}

138 It was previously shown that CCR2/5+ CD4 T cells from the blood migrate in response to CCL2 139 and multiple other chemokines ${ }^{32}$. Using a transwell migration assay, we found that lymphoid 140 CCR2/5+ cells display a chemotactic response to CCL2 (Figure 4A). CCL2 treatment has been 141 reported to increase the permissivity of blood-derived T cells to HIV infection ${ }^{41}$. However, we did 142 not observe that exogenous CCL2 affected HIV infection of tonsil-derived CD4 T cells (Figure 4143 -figure supplement 4). 
145 To assess the intrinsic permissiveness of CCR2/5+ cells to HIV infection, we sorted fresh tonsil T

146 cells and exposed them to GFP reporter viruses expressing either the NL4-3 envelope (X4-tropic)

147 or BaL envelope (R5-tropic). These cells supported productive infection by both viral strains in

148 the absence of ex vivo stimulation, (Figure 4B and $4 \mathrm{C}$ ), demonstrating that in their basal state

149 tonsil CCR2/5+ CD4 T cells were permissive to HIV infection.

151 Of note, exposure to R5-tropic virus caused rapid loss of surface expression of CCR2 in sorted 152 cells (Figure 4D). This decrease in CCR2 occurred within 24 hours in both infected cells (GFP+) 153 and bystander cells (GFP-) (Figure 4D shows all cells, of which GFP+ are $<5 \%$ ). This effect was 154 not observed following X4-tropic viral infection (Figure 4D, solid lines). A similar downregulation 155 of CCR5 was observed when the R5-tropic envelope was tested. Since this effect was 156 independent of productive infection (observed in GFP-cells), it likely reflects internalization of

157 CCR2 and CCR5 triggered by the binding of the viral envelope. These results highlight the 158 necessity of sorting cells based on their chemokine receptor expression prior to infection, and 159 underscore how exposure to R5-tropic envelope may confound detection and analysis of both 160 CCR5 and CCR2 expression on CD4 T cells.

\section{CCR2/5+ cells support latent infection by HIV}

163 Only a fraction of tonsillar CD4 T cells (5-10\%) undergo productive infection with HIV in the 164 absence of exogenous stimuli. An additional small fraction of cells become latently infected $42,43$. 165 To test whether CCR2/5+ cells were able to support latent infection, the cells were sorted as 166 above, then infected with a luciferase reporter virus in the presence of saquinavir (a viral protease 167 inhibitor) to prevent viral spread. The cells were then allowed to rest in the presence of ART to 168 establish latency, as previously described ${ }^{43}$. After five days in culture, the cells were stimulated 169 for 24 hours with anti-CD3/anti-CD28 antibodies in the presence of the integrase inhibitor, 
170 raltegravir, to ensure measurement of post-integration latency. Luciferase expression was

171 measured as a readout of viral reactivation. CCR2/5+ cells underwent similar HIV reactivation

172 after stimulation as CCR2/5-negative memory cells, and significantly greater reactivation than

173 CCR2-/5+ cells (Figure 4E). These findings showed that HIV could establish latent infection in

174 tonsil CCR2/5+ cells ex vivo.

175

176 We also measured the survival of CCR2/5+ cells following infection with both X4 and R5-tropic

177 virus. We found that the fraction that died following infection was quite similar to that of total tonsil

178 CD4 cells, with approximately two-thirds of cells surviving 48 hours after infection (Figure 4-

179 figure supplement 5). Together, these results show that HIV infection of CCR2/5+ cells can result

180 in multiple outcomes: productive infection, latent infection, or death.

\section{CCL2 blockade reduces seeding of the latent HIV reservoir in humanized mice}

183 To understand whether CCL2 played an active role in establishment of the HIV reservoir during

184 acute infection, we used a bone marrow, liver, thymus (BLT)-humanized mouse model of HIV.

185 This model utilized R5-tropic virus allowing the establishment of a latent HIV reservoir in human

186 lymphoid tissue that persists despite ART ${ }^{44}$. Mice were treated with a blocking anti-CCL2 antibody

$187(n=35)$ or an isotype control antibody $(n=34) 24$ hours prior to and during repeated intrarectal HIV

188 inoculations that occurred daily for 5 days (see Figure $5 \mathrm{~A}$ ). The intrarectal infection protocol

189 employed was previously shown to produce $\sim 50 \%$ infection rates ${ }^{45}$ and was selected to

190 recapitulate mucosal transmission. At day 7 post-infection, mice were switched to ART-infused

191 chow containing tenofovir disproxil-fumerate (Viread), emtricitabine (Emtriva), and raltegravir

192 (Isentress). At day 11 post-infection, anti-CCL2 or control antibody treatment was discontinued.

193 Mice were maintained on ART chow until week 12, and then switched to normal chow. Following

194 treatment interruption, blood was drawn weekly to assess viral rebound. Five animals (14.7\%) in 
195 the control antibody group exhibited detectable plasma viremia while no animals in the CCL2

196 blockade group developed detectable viremia (Fisher's exact $p=0.0248$ ) (Figure 5B). At week 16,

197 the animals were euthanized, and splenic tissue was harvested to measure HIV proviral DNA. In

198 total, 16 animals (47\%) from the isotype control arm had detectable HIV, compared to 5 (14\%)

199 from the CCL2-antibody treated group (Fisher's exact $p=0.0041$ ). Together, these findings

200 suggested that treatment with the anti-CCL2-blocking antibody, but not an isotype-control

201 antibody, significantly reduced seeding of the latent HIV reservoir in vivo.

202

\section{CCR2/5+ cells harbor HIV provirus in vivo}

204 To confirm that CCR2/5+ cells played a role in formation of the latent reservoir in people living 205 with HIV on ART, we examined if CCR2/5+ CD4 T cells from such individuals were enriched in 206 HIV proviruses. Fresh leukapheresis samples were obtained from nine ART-suppressed donors 207 from the SCOPE ("Observational Study of the Consequences of the Protease Inhibitor Era") 208 cohort at the University of California San Francisco and San Francisco General Hospital 209 (ClinicalTrials.gov Identifier: NCT00187512) (Figure 6-table supplement 2). From these 210 samples, CD4 T cells were sorted into naïve (CD45RO-) and memory (CD45RO+) cell

211 populations. The memory population was further separated based on the surface expression of 212 CCR2 and CCR5 (Figure 6A).

214 To quantify proviral levels, genomic DNA from sorted cells was isolated and subjected to ALU215 Gag droplet digital qPCR to detect integrated HIV provirus. This technique is based on a nested 216 PCR, in which an Alu-Gag amplicon is pre-amplified and a second internal set of primers + probe 217 is used to detect HIV. Using this assay, we observed that CCR2/5+ cells contained significantly 218 higher levels of integrated HIV than CCR2/5- memory cells or naïve cells (Figure 6 B-D). 219 Additionally, by comparing the levels of HIV DNA in the sorted populations to that in the total 
220 population of sorted CD4 T cells, we were able to quantify the percentages of total HIV provirus

221 in each cell population for each donor (Figure $6 \mathrm{C}$ and D). Considerable individual to individual

222 differences were observed. One individual exhibited a reservoir that was nearly $90 \%$ within the

223 CCR2/5+ population, while in others this percentage was lower. The median percentage of HIV

224 provirus within the CCR2/5+ cells was $37 \%$ (Fig 6D). Importantly, the CCR2/5+ cells had the

225 highest proportion of integrated HIV of all the sorted subsets. These results suggested that

226 CCR2/5+ cells formed a significant fraction of the latent HIV reservoir in vivo.

\section{DISCUSSION}

229 Chemokines and chemokine receptors have long been recognized to play important roles in HIV 230 biology. For example, the CCR5 and CXCR4 chemokine receptors function as coreceptors for 231 HIV entry, ${ }^{46,47}$ while the beta-chemokines, MIP-1 $\alpha$, MIP-1 $\beta$, and RANTES, act as potent inhibitors 232 of R5-tropic virus infection due to their ability to bind to and downregulate membrane expression 233 of CCR5 ${ }^{48}$.

235 Various HIV proteins including HIV gp120, Tat, Nef, and p17 can activate expression of different 236 chemokines including CCL2, CCL3, CCL4, and CCL5 involving effects on both infected and 237 bystander cells ${ }^{14}$. During HIV infection, CCL2 is prominently and rapidly expressed. However, 238 CCL2 production is not protective for the host, rather this chemokine promotes HIV infection and 239 spread both through the recruitment of new target cells (monocytes and CD4 T cells) and by 240 enhancing HIV replication via CCR2 signaling. CCL2 plays an important role in the development 241 of HIV-associated Neurocognitive Disorder (HAND) by enhancing blood-brain barrier permeability 242 and recruiting macrophages and activated T cells resulting in a chronic inflammatory encephalitis 
243 16-20. Similarly, CCL2 has been linked to other chronic inflammatory responses occurring in

244 multiple sclerosis, rheumatoid arthritis and various kidney diseases ${ }^{31,49}$.

246 Regarding HIV latency, the initial latent reservoir is formed within a few hours to a few days after

247 HIV infection. Central memory CD4 T cells are recognized as an important, self-renewing subset

248 of cells harboring latent provirus. The mechanisms underlying rapid seeding of the HIV reservoir

249 in these long-lived memory CD4 T cells remain unclear. Our studies now suggest that high level

250 production of CCL2 in tissue zones of HIV infection and inflammation recruits CCR2/5+ central

251 memory CD4 T cells likely contributing to rapid establishment of the latent HIV reservoir.

253 An additional mechanism of CCL2 induction by HIV

254 Cell-to-cell infection is fundamental to the pathogenesis and spread of HIV infection ${ }^{21-23,}{ }^{50,51 .}$

255 Early in our studies of tonsillar lymphocytes, we noted similar patterns of antiviral drug inhibition

256 for the production of CCL2 and type I interferons and the pyroptotic response that accompanies

257 abortive HIV infection of nonpermissive bystander cells (inhibition by entry inhibitors and NNRTI's

258 but no inhibition by NRTI's or integrase inhibitors). Pyroptosis and IFN1 production both involve

259 IFI16 sensing of incomplete HIV reverse transcripts accumulating in abortively infected,

260 nonpermissive bystander CD4 T cells present in lymphoid tissue ${ }^{25,26 .}$ These responses do not

261 occur with blood CD4 T cells although coculture of blood and lymphoid tissue cells confers

262 pyroptotic sensitivity to the CD4 T cells. ${ }^{21,25,26}$. Like pyroptotic cell death, CCL2 production occurs

263 in lymphoid, but not blood, CD4 T cells in our culture system (Figure 1 and Figure 1-figure

264 supplement 1). Others have previously shown that IFI16 signaling via STING drives IRF3

265 phosphorylation and Type I IFN production ${ }^{27}$; and further, that STING stimulates CCL2 production

266 by activating STAT6 ${ }^{28}$. When sgRNAs targeting IFI16 and STING were deployed with Cas9 RNPs 
267 to knockout these genes in lymphoid CD4 T cells, a partial decline in CCL2 production following

268 HIV infection was observed. In contrast to the STING and IFI16 gene deletions, knockout of cGAS,

269 a primary activator of STING ${ }^{29}$, only trended to decreasing CCL2 production not reaching

270 statistical significance.

272 Of note, the IFI16 and STING knockouts only partially ablate production of CCL2 in the HIV-

273 infected CD4 T cells. This likely is due to the fact that CCL2 production during HIV infection

274 occurs through multiple mechanisms. As noted above, HIV gp120 ${ }^{52-54}$, Tat ${ }^{55-57}$, Nef ${ }^{58}$, and p17

$275{ }^{59}$ have all been shown to activate CCL2. Our findings now add an additional mechanism

276 underlying CCL2 release during HIV infection involving IFI16 sensing of abortive reverse

277 transcription products coupled with STING signaling.

CCR2/5+ lymphocytes are primarily central memory cells in lymphoid tissue

280 CCL2 attracts cells that express CCR2 to areas of tissue inflammation. These cells can include

281 monocytes, CD4 T cells, and NK cells. Of note, CCR2 and CCR5 share $73 \%$ sequence

282 homology, are both found on the long arm of chromosome 17, and likely arose as a result of

283 gene duplication 60,61 . While the circulating CCR2/5+ CD4 T cells in blood are predominantly

284 effector memory cells ${ }^{32}$, the CCR2/5+ cells in the lymphoid tissue display a central memory

285 phenotype (Figs. 2 and 3). This pattern of chemokine receptor expression is intriguing in the

286 context of HIV infection as it provides a potential pathogenic link between target cell recruitment

287 (CCR2), infectability (CCR5), and rapid establishment of a long-lived latent reservoir within

288 central memory T cells (CCR7). 


\section{CCR2/5+ cells are targets of HIV infection}

290 We find that sorted CCR2/5+ cells from unstimulated tonsils are permissive to HIV infection

291 (Figure 4). However, it is important to sort these cells prior to infection before R5-tropic viruses

292 induce a downregulation of surface CCR2 changing the cell's phenotype (Figure 4D). We suspect

293 that this loss of CCR2 expression is due to viral envelope interactions with CCR2. Non-infected

294 bystanders (GFP-) as well as infected cells (GFP+) exhibit downregulation of CCR2 following

295 exposure to R5-tropic, but not X4-tropic NL4-3. In addition to the homology shared by CCR2 and

296 CCR5, previous studies have described CCR2 binding by HIV Env, and multiple HIV entry

297 inhibitors block both CCR5 and CCR2-including TAK-779 and cenicriviroc 62. Thus, our

298 observation of HIV envelope-mediated downregulation of CCR2 is likely explained by the

299 similarity of CCR2 and the canonical CCR5 HIV co-receptor with envelope binding sufficing to

300 trigger internalization of both receptors.

By attracting target cells to become productively infected, the CCL2/CCR2 axis could contribute

303 to acute HIV pathogenesis amplifying productive, spreading infection. Additionally, CCR2/5+ cells

304 may undergo latent infection facilitating early formation of the reservoir. Using an in vitro model

305 to measure HIV reactivation, we find that CCR2/5+ cells harbor significant levels of latent provirus

306 that can be induced by subsequent T cell receptor stimulation (Figure 4E).

308 Mucosal origins of CCR2/5+ cells

309 As the primary route of HIV infection is through mucosal tissues, the integrin expression profile of

310 the CCR2/5+ population is particularly interesting. These cells express high surface levels of the 311 CD49d, CD29, and a4 $\beta 7$ integrins (Figure 3) that play a key role in mucosal trafficking ${ }^{63}$. CCR2+

312 CD4 T cells are also recruited to the ileum in inflammatory bowel disease ${ }^{64}$. Thus, CCR2/5+ CD4

313 T cells are likely mucosal in origin, or alternatively home to mucosa or mucosa-associated 
314 lymphoid tissue (MALT). These cells may be involved in establishment of reservoirs in MALT even

315 before migration into secondary lymphoid organs.

317 In Vivo Blockade of CCL2 reduces HIV reservoir formation

318 We next sought to test the biological relevance of CCL2 action in vivo in the formation of the latent

319 HIV reservoir in BLT-humanized mice 44, 45, 65 and our studies indicated that antibody-mediated 320 blockade of CCL2 significantly reduced the formation of the HIV reservoir, as measured by 321 decreased detection of plasma viremia following ART withdrawal and total detectable HIV at 322 necropsy (Figure 5). CCL2 blockade was administered one day prior to HIV exposure. We also 323 intentionally selected a short infection period of only 6 days before initiation of ART to evaluate 324 the establishment of the most rapidly formed stable reservoir.

326 Our planned follow-on investigations in the BLT-humanized mouse model including lengthening 327 the time of infection could not be performed due to the Presidential Executive Order banning 328 government scientists (including K.J.H.) from using human fetal tissue in research. Despite these 329 limitations, our findings are consistent with anti-CCL2 blockade decreasing early seeding of the 330 HIV reservoir in vivo and merit further examination. CCR2/5+ cells serve as hosts for a substantial fraction of the latent HIV reservoir in humans

333 Long-term effective ART contracts the population of HIV-infected cells around a core reservoir of 334 cells infected prior to treatment. Our findings indicate that on average CCR2/5+ cells harbor $\sim 35 \%$ 335 of the reservoir when blood cells are analyzed from HIV-infected individuals on ART. However, 336 we also noted marked differences in the fraction of the reservoir residing in CCR2/5+ cells among 337 the 9 individuals analyzed (Fig 6D). In one individual, nearly $90 \%$ of the latent reservoir was found 338 in the CCR2/5+ cells. These findings suggest that CCL2 may play an important role in latent 
reservoir seeding in many but not all infected individuals. It is certainly possible that the underlying mechanism of infection and level of inflammation in lymphoid tissues may vary-impacting levels

341 of CCL2 that are released, and the extent to which CCR2/5+ chemoattraction occurs. Additionally,

342 the duration of infection prior to treatment may allow for spread of the reservoir, and although

343 CCR2 + cells may be initially favored, the phenotype of the reservoir likely broadens during chronic

344 infection. CCR2-negative cells also harbored HIV provirus in all assayed individuals (Figure 6).

345 Therefore, CCR2 expression certainly does not perfectly mark the HIV reservoir in vivo.

347 A limitation of most reservoir studies, including this one, is that human samples are often limited 348 to peripheral blood donated by HIV-infected individuals, and therefore fail to sample the tissue 349 reservoir. However, circulating cells of the blood originate from tissue sites. The effector memory 350 CCR2/5+ cells we find containing HIV provirus are likely daughters of the initially infected 351 lymphoid tissue-derived CCR2/5+ central memory cells.

353 Together, our results demonstrate that lymphoid tissue CD4 T cells rapidly produce CCL2 as part 354 of an innate inflammatory response launched during HIV infection. Among multiple mechanisms, 355 IFI16 sensing of HIV DNA and signaling via STING contributes to rapid release of the CCL2 356 chemokine that can quickly recruit CCR2/5+ central memory cells to the zone of HIV-associated 357 inflammation. Within these infection zones, some cells may become productively infected while 358 others undergo latent infection and yet others die. Finally, CCR2/5+ central memory cells take up 359 residence in peripheral lymphoid organs, harboring latent HIV provirus, contributing to the 360 persistence of the stable reservoir. Our findings argue for a role of the CCL2/CCR2 axis in early 361 seeding of the latent reservoir illustrating how the innate immune response may, in this case, 362 promote viral persistence. 
MATERIALS AND METHODS

\section{Experimental Model and Subject Details}

\section{Human samples}

366 Blood from HIV-infected individuals was obtained from volunteers participating in the SCOPE 367 cohort ${ }^{66}$. Participants gave their informed consents as part of the SCOPE cohort. Specific 368 characteristics of these participants and their ART regimens are summarized in Table S2.

\section{Humanized TKO-BLT mice}

371 Male and female C57BL/6 Rag2-/-yc-/-CD47-/- (TKO) mice were humanized using the bone 372 marrow, liver, thymus (BLT) method as previously described ${ }^{44}$. All animal studies were performed 373 after approval of the animal study protocol by the AAALAC-accredited Rocky Mountain

374 Laboratories, National Institute of Allergy and Infectious Diseases, National Institutes of Health 375 (USA) Institutional Animal Care and Use Committee. The mice were housed under specific 376 pathogen-free conditions, properly anesthetized during procedures and monitored daily. Donor 377 tissues for humanization were obtained with informed consent following the guidelines and 378 regulations of $\mathrm{NIH}$ and the Office of Human Subjects Research Protection. All humanized mouse 379 studies were initiated prior to the Presidential executive order banning government research using 380 fetal tissue.

382 Humanized mice were treated intraperitoneally with $200 \mu \mathrm{g}$ anti-CCL2 antibody (2H5) or isotype 383 control 24 hours prior to infection followed by $100 \mu \mathrm{g}$ administered every 48 hours for a total of

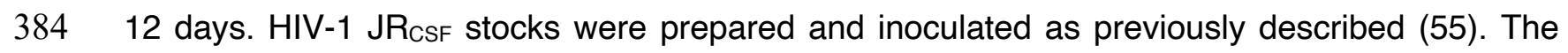
385 mice were challenged with $5 \times 10^{4}$ TCIU of HIV via the anal route at day 0 and repeated every 24 386 hours for 4 additional days. At day 6 post-infection, the mice were bled retroorbitally. At day 7, the 387 mice were free-fed dyed red ART-infused chow (Modified LabDiet® PicoLab® Mouse Diet 20, 
5058; supplemented with 1250 ppm Emtriva (ematricitabine), 1630 ppm Viread (tenofovir disproxil-fumerate), and 10,688 ppm Isentress (raltegravir)) until 12 weeks post infection, when

390 ART was discontinued. Mice were bled at 6 weeks post-infection to test for suppression of viremia

391 and weekly following ART-interruption until the euthanasia time-point at 16 weeks post-infection.

\section{Primary-cell cultures}

393 Specimens derived from HIV-negative human blood and tissue were de-identified before receipt

394 by the laboratory and are thus exempt from human subject research per the UCSF Human

395 Research Protection Program Institutional Review Board. Human healthy tonsils and spleens 396 were obtained from the Cooperative Human Tissue Network (https://www.chtn.org). HIV-negative 397 donor blood was obtained from Vitalant (https://www.vitalant.org).

399 Human lymphoid aggregate culture (HLAC) prepared from tonsil or spleen was cultured in HLAC medium: RPMI supplemented with 15\% heat-inactivated fetal bovine serum (FBS), $100 \mathrm{mg} / \mathrm{ml}$

401 gentamicin, $200 \mathrm{mg} / \mathrm{ml}$ ampicillin, $1 \mathrm{mM}$ sodium pyruvate, $1 \%$ nonessential amino acids, $2 \mathrm{mM} \mathrm{L-}$ 402 glutamine, and $1 \%$ fungizone at $37^{\circ} \mathrm{C}$ in $5 \% \mathrm{CO}_{2}$ incubator.

404 Concentrated white blood cell preparations from healthy volunteers were obtained from Vitalant. 405 PBMCs were cultured in RPMI supplemented with 10\% FBS, $1000 \mathrm{U} / \mathrm{ml}$ Penicillin and $1 \mathrm{mg} / \mathrm{ml}$ 406 Streptomycin and $2 \mathrm{mM} \mathrm{L-glutamine,} \mathrm{at} 37^{\circ} \mathrm{C}$ in $5 \% \mathrm{CO}_{2}$ incubator.

\section{Cell line}

409 HEK293T cells were transfected with various molecular clones of HIV to produce high titer virus 410 preparations. Cells were cultured in DMEM supplemented with 10\% FBS, $1000 \mathrm{U} / \mathrm{ml}$ Penicillin 411 and $1 \mathrm{mg} / \mathrm{ml}$ Streptomycin and $2 \mathrm{mM} \mathrm{L}$-glutamine, at $37^{\circ} \mathrm{C}$ in $5 \% \mathrm{CO}_{2}$ incubator. 


\section{Virus strains}

414 HIV molecular clones (pNL4-3-GFP, pBaL-GFP, and pNL4-3-Luciferase) were purified from E.

415 coli and used to transfect HEK293T cells.

\section{Primary cell isolation \& culture}

417 Fresh human tonsil tissue or splenic tissue was processed and cultured as previously described

$418{ }^{24}$. Briefly, single-cell suspensions were prepared by mechanical disruption of the tonsil or spleen,

419 followed by sequential passage of cells through $70 \mu \mathrm{m}$ then $40 \mu \mathrm{m}$ strains. Single-cell

420 suspensions were purified by density gradient centrifugation using Ficoll-Hypaque (GE), the

421 mononuclear cell layer was isolated and washed twice with FACS buffer and then analyzed by

422 flow or mass cytometry, or alternatively cultured in HLAC medium. PBMCs were similarly purified

423 by density gradient centrifugation using Ficoll-Hypaque.

\section{CD4 T cell isolation}

426 CD4 T cells were purified from lymphoid tissue or PBMC-derived mononuclear cells by negative 427 magnetic depletion using the EasySep Human CD4+ T Cell Enrichment Kit (Stem Cell), per the 428 manufacturer's protocol.

\section{$430 \quad$ HIV infection (overlay model)}

431 Overlay infections were carried out as previously described ${ }^{21}$. Briefly, HEK293T cells were 432 seeded in 24-well tissue culture plates at a density of $1.6 \times 10^{5}$ cells/well and transfected with 50$433100 \mathrm{ng} /$ well of pNL4-3-GFP using Fugene HD (Promega) transfection reagent, per the 434 manufacturer's protocol. The medium was replaced after 16 hours, and CD4 T cells, purified as 435 described above, were added. Cells or supernatants were harvested at time points indicated for 436 each experiment. 


\section{HIV infection (spinoculation model)}

439 Concentrated HIV was produced by transfecting 5-10 x 106 HEK293T cells per T150 flask with 440 pNL4-3.GFP, pBAL.GFP, or pNL4-3.Luciferase, using Fugene HD per the manufacturer's

441 protocol. The medium was replaced at 16 hours after transfection and supernatant harvested at

442 48- and 72-hours post-transfection. Supernatant containing viruses was passed through a 0.22

$443 \mu \mathrm{m}$ filter and virus was pelleted at $25,000 \times \mathrm{g}$ for 2 hours at $4^{\circ} \mathrm{C}$. Following resuspension of the

444 pellet in RPMI, the concentrated viruses were aliquoted and frozen at $-80^{\circ} \mathrm{C}$. Virus concentration

445 was determined by quantitation of p249ag as previously described ${ }^{21} .100 \mathrm{ng}$ of virus was generally

446 added to the cell populations cultured at $1 \times 10^{6} \mathrm{cells} / \mathrm{mL}$ in $100 \mu \mathrm{L}$ in 96 -well round-bottom tissue

447 culture plates. The plate was spun at $900 \times \mathrm{g}$ for 2 hours at room temperature and then cultured

448 at $37^{\circ} \mathrm{C}$ in $5 \% \mathrm{CO}_{2}$ incubator.

\section{Analysis of cytokine expression}

451 Quantitative RT-PCR was used to assess cytokine mRNA expression. Cells were harvested 18-

45248 hours following culture or infection as described for the various experiments, and RNA was

453 purified using RNAeasy Kit (Qiagen) per the manufacturer's protocol with inclusion of DNAse

454 treatment. Purified RNA was quantified, and cDNA was prepared using the SuperScript® III First-

455 Strand Synthesis kit (Thermo Fisher). RNA, oligo(dT) 20 and dNTPs were combined and incubated

456 at $65^{\circ} \mathrm{C}$ for 5 minutes, then cooled to $4^{\circ} \mathrm{C}$. RT buffer, $\mathrm{MgCl}_{2}, \mathrm{DTT}, \mathrm{RNaseOUT}{ }^{\mathrm{TM}}$, and

457 SuperScript ${ }^{\circledR}$ III RT were added per the manufacturer's protocol and incubated at $50^{\circ} \mathrm{C}$ for 50

458 minutes. The reaction was terminated by heating to $85^{\circ} \mathrm{C}$ for 5 minutes and cDNA was stored at

$459-20^{\circ} \mathrm{C}$. Following cDNA production, quantitative PCR was carried out using Taqman Gene

460 Expression Assays (Thermo Fisher, see Key Reagents Table for specific Assay IDs) per the

461 manufacturer's protocol. Both GAPDH and 18S mRNA were measured, and the geometric means 
462 of these housekeeping genes were used to normalize expression (delta cycle threshold) of query

463 transcripts.

465 Secreted CCL2 protein was measured using the Meso Scale Discovery (MSD) platform.

466 Supernatants from cells cultured as described were harvested and clarified by centrifugation at

$4671000 \times \mathrm{g}$ for 10 minutes. Undiluted supernatant was applied to the V-PLEX Human MCP-1 Kit

468 (Meso Scale Discovery) and CCL2 was measured using a recombinant standard, per the 469 manufacturer's protocol.

\section{Cas9 RNP genomic editing}

472 Nucleofection was performed using in vitro assembled Cas9RNP nucleofection as previously 473 described ${ }^{67}$. Recombinant Cas9 protein derived from S. pyrogenes engineered with two nuclear 474 localization signals and an HA tag on the C-terminus was obtained from the QB3 Macrolab at the 475 University of California Berkeley. Multiple guide RNAs were tested, and two were selected for 476 each target gene that showed high knockdown efficiency in multiple donors (see Key Resources

477 Table for guide sequences). Guide RNA and tracrRNA suspended in 10mM Tris-HCL (pH 7.4) 478 were mixed at $1: 1$ ratio, at a final concentration of $40 \mu \mathrm{M}$ and incubated for 30 minutes at $37^{\circ} \mathrm{C}$. 479 The guide RNA mixture was added to $40 \mu \mathrm{M}$ recombinant Cas9 and incubated at $37^{\circ} \mathrm{C}$ for 15 480 minutes to allow for assembly of the guide RNA:Cas9 RNPs.

482 HLAC cells were stimulated for 3 days with plates coated with $10 \mu \mathrm{g} / \mathrm{mL}$ anti-CD3 (UCHT1, Tonbo 483 Biosciences) and $10 \mu \mathrm{g} / \mathrm{mL}$ anti-CD28 (CD28.2, Tonbo Biosciences). CD4 T cells were purified 484 as described above and $3 \times 10^{5}$ CD4 T cells were pelleted in a V-bottom plate and resuspended 485 in $20 \mu \mathrm{L}$ P3 buffer, from the P3 Primary Cell 96-well Nuclofector kit (Lonza). $3 \mu \mathrm{L}$ of the assembled 
487 The cuvettes were loaded into the 4D-Nucleofector (Lonza) and electroporated using program

$488 \mathrm{EH}-115.80 \mu \mathrm{L}$ of pre-warmed HLAC medium was gently added to each well and the cells were

489 allowed to recover for 30 minutes at $37^{\circ} \mathrm{C}$, before re-stimulating overnight on plates as above.

490 Following Cas9RNP-mediated editing, the cells were removed from stimulation and rested for one

491 week before infection or subsequent analyses. Knockout efficiencies were measured using

492 immunoblotting or intracellular flow cytometry.

493

\section{Immunoblotting}

495 Cell lysates were prepared by addition of Laemmli Lysis Buffer and heat denaturization at $90^{\circ} \mathrm{C}$ 496 for 30 minutes. Lysates were electrophoresed on a 4-12\% Bis/Tris gel (Thermo Fisher) at 120V 497 for 90 minutes. Proteins were transferred to a PVDF membrane using an iBlot 2 apparatus per 498 the manufacturer's protocol (Default program P1). Following transfer, the membrane was blocked 499 with $5 \% \mathrm{w} / \mathrm{v}$ dry skim milk dissolved in PBS $+0.1 \%$ Tween-20 (PBS-T) for 1 hour at room 500 temperature with rocking. Blocked membranes were incubated with primary antibodies (see Key 501 Resources Table), diluted in blocking buffer $(1: 1,000)$ and incubated with rocking overnight at $5024^{\circ} \mathrm{C}$. The following day, membranes were washed in PBS-T and incubated with HRP-conjugated 503 secondary antibody diluted 1:10,000 in blocking buffer for 2 hours at room temperature with 504 continuous rocking. After secondary incubation, the membranes were washed and TMB substrate 505 was added. The reaction was allowed to proceed for 5 minutes, and light was measured by 506 exposure to film.

$508 \quad$ Flow cytometric analysis \& cell sorting

509 Flow cytometry was performed at the Gladstone Institutes Flow Cytometry Core Facility using two 510 instruments: an LSR II (BD Biosciences, San Diego, CA, US) and FACSAria II (BD Biosciences, 511 San Diego, CA, US). Cells were resuspended in PBS and Zombie Live/Dead (Biolegend) stain 
512 was added per the manufacturer's protocol. Subsequently, FACS buffer (PBS + 2mM EDTA + 5\%

513 BSA) was added as well as antibodies for cell surface staining (see Key Resources Table). Cells

514 were washed and sorted live; or fixed in $2 \%$ paraformaldehyde (PFA) prior to analysis. For

515 intracellular antigen detection, following cell surface staining, cells were permeabilized using the

516 Foxp3/Transcription Factor Staining Buffer Set (Thermo Fisher) following the manufacturer's

517 protocol.

519 Fluorescence-activated cell sorting was performed on unfixed live cells, following isolation and 520 surface staining as described above. Single cells from a lymphocyte scatter gate were gated as 521 "live" (zombie low/negative, see Key Resources Table), and subsequently as CD3+/4+ T cells. 522 CD4+ T cells were then sorted as naïve (CD45RO-) or memory (CD45RO+) and further sub523 divided as CCR2-/5-, CCR2+/5-, CCR2-/5+, or CCR 2+/5+, (see Figure 6 for example). Cells were 524 sorted into ice cold HLAC medium for functional studies as described in the text; or sorted into ice 525 cold PBS, pelleted, and genomic DNA isolated for HIV provirus measurements.

\section{Mass cytometric analysis}

528 Mass cytometric analyses was performed as previously described ${ }^{68}$. Cells were isolated from 529 fresh PBMCs or HLAC as described above and stained with a panel of lanthanide metal530 conjugated antibodies (See Table S1). Antibody staining was performed in a volume of $100 \mu \mathrm{L}$ 531 for $45 \mathrm{~min}$, treated with 139In-DOTA-maleimide (Macrocyclics) to label dead cells, and fixed 532 overnight with PBS $+2 \%$ PFA. Cells were permeabilized with FoxP3 Fix/perm buffer

533 (ThermoFisher) per the manufacturer's protocol, then labelled with 1:4,000 191/193Ir DNA 534 intercalator (Fluidigm). Cells were washed, resuspended in distilled water, and analyzed on a 535 CyTOF2 (Fluidigm) at the UCSF Parnassus Flow Cytometry Core. EQ calibration beads 536 (Fluidigm) were included and used for normalization across runs. 


\section{Chemotaxis measurement}

538 CCR2/5+ CD4+ T cells were purified by FACS and suspended at $1 \times 10^{6} \mathrm{cells} / \mathrm{ml}$ in RPMI with

$5390.5 \%$ BSA and $25 \mathrm{mM}$ HEPES. $100 \mu \mathrm{l}$ of sorted cells were added to each transwell insert with

540 6.5-mm-diameter membranes containing 3.0- $\mu \mathrm{m}$ pores (Corning). The cells were pre-incubated

541 for $30 \mathrm{~min}$ at $37^{\circ} \mathrm{C}$, and the inserts transferred into wells with chemotaxis medium containing

542 either CCL2 (1 $\mu \mathrm{g} / \mathrm{mL}$, PeproTech) or medium alone. Cells in the lower wells were harvested after

5433 hours at $37^{\circ} \mathrm{C}$, and the migrated cells were counted using AccuCount Particles on an LSR II

544 cytometer.

\section{In vitro latency}

547 As previously described, purified CD4 T cells were initially infected and then rested in the

548 presence of ART to establish in vitro latency ${ }^{43}$. Briefly, tonsil-derived purified resting

549 (unstimulated) memory CD4 T cells were sorted based on their expression of CCR2 and 5 as

550 described above. 100 ng of purified NL4-3-Luciferase was added to the sorted cells and they were

551 spinoculated as described above and $5 \mu \mathrm{M}$ saquinavir was added to limit infection to a single

552 round. Following 5 days of culture the cells were stimulated with anti-CD3/CD28 beads per the

553 manufacturer's protocol, in the presence of $30 \mu \mathrm{M}$ raltegravir. 24 hours after stimulation, luciferase

554 activity was measured as previously described 43.

556 HIV Alu-Gag droplet digital qPCR

557 Nested Alu-gag qPCR was performed, as previously described 69, 70 with minor modifications.

558 Briefly, genomic DNA was isolated using DNeasy kits using RNAse-treatment step (Qiagen) per

559 the manufacturer's protocol. A primary PCR to amplify integrated provirus used a forward ALU-

560 targeting primer at a concentration of $100 \mathrm{nM}$ and HIV-1 gag reverse primer at $600 \mathrm{nM}$. Pre-

561 amplification was performed with Taq polymerase (Qiagen) for 20 cycles. 
$5621 \mu \mathrm{L}$ of the above PCR product was combined with $10 \mu \mathrm{L}$ Gene Expression Master Mix (Applied

563 Biosciences), $8 \mu \mathrm{L}$ water, $1 \mu \mathrm{L}$ probe mix (Pre-made 20X mix: $5 \mu \mathrm{M} \mathrm{MH531} \mathrm{\&} \mathrm{MH532} \mathrm{primers,} 4 \mu \mathrm{M}$

564 LRT probe). The PCR mixture was partitioned using a QX200 droplet generator (Bio-Rad), and

565 the droplets were amplified for ( $95^{\circ}$ for $15 \mathrm{~s}, 60^{\circ}$ for $30 \mathrm{~s} \times 35$ cycles). Positive and negative droplets

566 were then detected on a QX200 droplet reader (Bio-Rad), and the results quantified using

567 QuantaSoft software.

\section{Measurement of HIV in TKO-BLT humanized mice}

570 Plasma HIV RNA was isolated with the QIAamp Viral RNA Kit (Qiagen) and quantified using the

571 Abbott RealTime HIV-1 Amplification Reagent Kit following the manufacturer's protocols.

572 Depending on the available sample volume, the detection limit was $375 \mathrm{cp} / \mathrm{mL}$ during follow-up

573 or $150 \mathrm{cp} / \mathrm{mL}$ at the time of euthanasia. For the quantification of HIV DNA, genomic DNA of

574 splenocytes was isolated using QIAamp DNA blood mini kit (Qiagen) and subjected to a probe-

575 based real-time PCR approach, as previously described 71, 72. Briefly, HIV-specific and control

576 (hCD3) DNA sequences were pre-amplified (12 cycles) in a TProfessional TRIO Thermocycler

577 (Biometra). The pre-PCR amplicons were subjected to quantitative real-time PCR analysis using

578 the Rotor-Gene Probe PCR Kit (Qiagen) performed in a Rotor-Gene Q instrument (Qiagen). Dual

579 labelled probes were used for CD3 (YAK-BHQ1) and HIV-DNA (6Fam-BHQ1) detection. Plasmids

580 encoding the corresponding amplicon regions or gDNA of cells harboring HIV-LTR sequences

581 were used as standard curves. ${ }^{72}$

\section{QUANTIFICATION AND STATISTICAL ANALYSIS}

583 Statistical details of individual experiments, including number of independent donors, mean

584 values, standard error of the mean (SEM), and $p$ values derived from statistical tests are described

585 in the figure legends and specified in the figures. Statistical analyses were performed using 
GraphPad Prism software versions $7 \&$ 8. p values $\leq 0.05$ were considered statistically significant.

For two-way column analyses, a Student's two-tailed t-test was used. ANOVA tests were used for multiple comparisons with post-tests for multiple comparisons (as noted within). Asterisk coding in figures is as follows: ${ }^{*} p \leq 0.05 ;{ }^{* *} p \leq 0.01 ;{ }^{* *} p \leq 0.001$. Data are presented as means with error bars indicating SEM unless otherwise stated.

DATA AND CODE AVAILABILITY

593 This study did not generate datasets.

\section{ACKNOWLEDGMENTS}

596 The authors thank Jane Srivastava and Nandhini Raman of the Gladstone Flow Cytometry Core,

597 the UCSF Diabetes Research Center for use of their CyTof instrument, the UCSF Parnassus Flow

598 Cytometry Core for CyTOF assistance, John C.W. Carroll for graphic arts, Francoise Chanut for 599 editorial assistance, and Robin Givens for administrative assistance.

COMPETING INTERESTS: None

602

603

604

605

606

\section{REFERENCES}

1. Whitney JB, Hill AL, Sanisetty S, Penaloza-MacMaster P, Liu J, Shetty M, Parenteau L, et al. Rapid seeding of the viral reservoir prior to SIV viraemia in rhesus monkeys. Nature. 2014;512(7512):74-77. PMCID: PMC4126858

2. Colby DJ, Trautmann L, Pinyakorn S, Leyre L, Pagliuzza A, Kroon E, Rolland M, et al. Rapid HIV RNA rebound after antiretroviral treatment interruption in persons durably suppressed in Fiebig I acute HIV infection. Nat Med. 2018;24(7):923-926. PMCID: PMC6092240

3. Henrich TJ, Hatano H, Bacon O, Hogan LE, Rutishauser R, Hill A, Kearney MF, et al. HIV1 persistence following extremely early initiation of antiretroviral therapy (ART) during acute HIV-1 infection: An observational study. PLoS Med. 2017;14(11):e1002417. PMCID: PMC5675377 
4. Chomont N, El-Far M, Ancuta P, Trautmann L, Procopio FA, Yassine-Diab B, Boucher G, et al. HIV reservoir size and persistence are driven by $\mathrm{T}$ cell survival and homeostatic proliferation. Nat Med. 2009;15(8):893-900. PMCID: PMC2859814

5. Siliciano JM, Siliciano RF. The Remarkable Stability of the Latent Reservoir for HIV-1 in Resting Memory CD4+ T Cells. J Infect Dis. 2015;212(9):1345-1347.

6. Murray AJ, Kwon KJ, Farber DL, Siliciano RF. The Latent Reservoir for HIV-1: How Immunologic Memory and Clonal Expansion Contribute to HIV-1 Persistence. J Immunol. 2016;197(2):407-417. PMCID: PMC4936486

7. Estes JD, Kityo C, Ssali F, Swainson L, Makamdop KN, Del Prete GQ, Deeks SG, et al. Defining total-body AIDS-virus burden with implications for curative strategies. Nat Med. 2017;23(11):1271-1276. PMCID: PMC5831193

8. Ochsenbauer C, Edmonds TG, Ding H, Keele BF, Decker J, Salazar MG, SalazarGonzalez JF, et al. Generation of transmitted/founder HIV-1 infectious molecular clones and characterization of their replication capacity in CD4 T lymphocytes and monocytederived macrophages. J Virol. 2012;86(5):2715-2728. PMCID: PMC3302286

9. Parker ZF, lyer SS, Wilen CB, Parrish NF, Chikere KC, Lee FH, Didigu CA, et al. Transmitted/founder and chronic HIV-1 envelope proteins are distinguished by differential utilization of CCR5. J Virol. 2013;87(5):2401-2411. PMCID: PMC3571396

10. Parrish NF, Gao F, Li H, Giorgi EE, Barbian HJ, Parrish EH, Zajic L, et al. Phenotypic properties of transmitted founder HIV-1. Proc Natl Acad Sci U S A. 2013;110(17):66266633. PMCID: PMC3637789

11. Gattinoni L, Lugli E, Ji Y, Pos Z, Paulos CM, Quigley MF, Almeida JR, et al. A human memory T cell subset with stem cell-like properties. Nat Med. 2011;17(10):1290-1297. PMCID: PMC3192229

12. Weiss L, Si-Mohamed A, Giral P, Castiel P, Ledur A, Blondin C, Kazatchkine MD, et al. Plasma levels of monocyte chemoattractant protein-1 but not those of macrophage inhibitory protein-1alpha and RANTES correlate with virus load in human immunodeficiency virus infection. J Infect Dis. 1997;176(6):1621-1624.

13. Ansari AW, Bhatnagar N, Dittrich-Breiholz O, Kracht M, Schmidt RE, Heiken H. Host chemokine (C-C motif) ligand-2 (CCL2) is differentially regulated in HIV type 1 (HIV-1)infected individuals. Int Immunol. 2006;18(10):1443-1451.

14. Covino DA, Sabbatucci M, Fantuzzi L. The CCL2/CCR2 Axis in the Pathogenesis of HIV1 Infection: A New Cellular Target for Therapy? Curr Drug Targets. 2016;17(1):76-110.

15. Stacey AR, Norris PJ, Qin L, Haygreen EA, Taylor E, Heitman J, Lebedeva M, et al. Induction of a striking systemic cytokine cascade prior to peak viremia in acute human immunodeficiency virus type 1 infection, in contrast to more modest and delayed responses in acute hepatitis B and C virus infections. J Virol. 2009;83(8):3719-3733. PMCID: PMC2663284

16. Cinque P, Vago L, Mengozzi M, Torri V, Ceresa D, Vicenzi E, Transidico P, et al. Elevated cerebrospinal fluid levels of monocyte chemotactic protein-1 correlate with HIV-1 encephalitis and local viral replication. AIDS. 1998;12(11):1327-1332. 
17. Yuan L, Qiao L, Wei F, Yin J, Liu L, Ji Y, Smith D, et al. Cytokines in CSF correlate with HIV-associated neurocognitive disorders in the post-HAART era in China. $J$ Neurovirol. 2013;19(2):144-149. PMCID: PMC4363104

18. Carvallo L, Lopez L, Che FY, Lim J, Eugenin EA, Williams DW, Nieves E, et al. Buprenorphine decreases the CCL2-mediated chemotactic response of monocytes. $J$ Immunol. 2015;194(7):3246-3258. PMCID: PMC4369415

19. Veenstra M, Leon-Rivera R, Li M, Gama L, Clements JE, Berman JW. Mechanisms of CNS Viral Seeding by HIV(+) CD14(+) CD16(+) Monocytes: Establishment and Reseeding of Viral Reservoirs Contributing to HIV-Associated Neurocognitive Disorders. MBio. 2017;8(5). PMCID: PMC5654927

20. Williams DW, Veenstra M, Gaskill PJ, Morgello S, Calderon TM, Berman JW. Monocytes mediate HIV neuropathogenesis: mechanisms that contribute to HIV associated neurocognitive disorders. Curr HIV Res. 2014;12(2):85-96. PMCID: PMC4351961

21. Munoz-Arias I, Doitsh G, Yang Z, Sowinski S, Ruelas D, Greene WC. Blood-Derived CD4 T Cells Naturally Resist Pyroptosis during Abortive HIV-1 Infection. Cell Host Microbe. 2015;18(4):463-470. PMCID: PMC4627664

22. Galloway NL, Doitsh G, Monroe KM, Yang Z, Munoz-Arias I, Levy DN, Greene WC. Cellto-Cell Transmission of HIV-1 Is Required to Trigger Pyroptotic Death of Lymphoid-TissueDerived CD4 T Cells. Cell Rep. 2015;12(10):1555-1563. PMCID: PMC4565731

23. Sanchez DJ, Miranda D, Jr., Marsden MD, Dizon TM, Bontemps JR, Davila SJ, Del Mundo LE, et al. Disruption of Type I Interferon Induction by HIV Infection of T Cells. PLoS One. 2015;10(9):e0137951. PMCID: PMC4574156

24. Doitsh G, Cavrois M, Lassen KG, Zepeda O, Yang Z, Santiago ML, Hebbeler AM, et al. Abortive HIV Infection Mediates CD4 T Cell Depletion and Inflammation in Human Lymphoid Tissue. Cell. 2010;143(5):789-801. PMCID: PMC3026834

25. Doitsh G, Galloway NL, Geng X, Yang Z, Monroe KM, Zepeda O, Hunt PW, et al. Cell death by pyroptosis drives CD4 T-cell depletion in HIV-1 infection. Nature. 2014;505(7484):509-514. PMCID: PMC4047036

26. Monroe KM, Yang Z, Johnson JR, Geng X, Doitsh G, Krogan NJ, Greene WC. IFI16 DNA sensor is required for death of lymphoid CD4 T cells abortively infected with HIV. Science. 2014;343(6169):428-432. PMCID: PMC3976200

27. Unterholzner L, Keating SE, Baran M, Horan KA, Jensen SB, Sharma S, Sirois CM, et al. IFI16 is an innate immune sensor for intracellular DNA. Nat Immunol. 2010;11(11):9971004. PMCID: PMC3142795

28. Chen H, Sun H, You F, Sun W, Zhou X, Chen L, Yang J, et al. Activation of STAT6 by STING is critical for antiviral innate immunity. Cell. 2011;147(2):436-446.

29. Sun L, Wu J, Du F, Chen X, Chen ZJ. Cyclic GMP-AMP synthase is a cytosolic DNA sensor that activates the type I interferon pathway. Science. 2013;339(6121):786-791. PMCID: PMC3863629

30. Matsushima K, Larsen CG, DuBois GC, Oppenheim JJ. Purification and characterization of a novel monocyte chemotactic and activating factor produced by a human myelomonocytic cell line. J Exp Med. 1989;169(4):1485-1490. PMCID: PMC2189236 
31. Deshmane SL, Kremlev S, Amini S, Sawaya BE. Monocyte chemoattractant protein-1 (MCP-1): an overview. J Interferon Cytokine Res. 2009;29(6):313-326. PMCID: PMC2755091

32. Zhang HH, Song K, Rabin RL, Hill BJ, Perfetto SP, Roederer M, Douek DC, et al. CCR2 identifies a stable population of human effector memory CD4+ T cells equipped for rapid recall response. J Immunol. 2010;185(11):6646-6663.

33. Sallusto F, Geginat J, Lanzavecchia A. Central memory and effector memory $T$ cell subsets: function, generation, and maintenance. Annu Rev Immunol. 2004;22:745-763.

34. Murray JM, Zaunders JJ, McBride KL, Xu Y, Bailey M, Suzuki K, Cooper DA, et al. HIV DNA subspecies persist in both activated and resting memory CD4+ $T$ cells during antiretroviral therapy. J Virol. 2014;88(6):3516-3526. PMCID: PMC3957951

35. Chachage M, Pollakis G, Kuffour EO, Haase K, Bauer A, Nadai Y, Podola L, et al. CD25+ FoxP3+ Memory CD4 T Cells Are Frequent Targets of HIV Infection In Vivo. $J$ Virol. 2016;90(20):8954-8967. PMCID: PMC5044822

36. Fromentin R, Bakeman W, Lawani MB, Khoury G, Hartogensis W, DaFonseca S, Killian

37. Kuo HH, Ahmad R, Lee GQ, Gao C, Chen HR, Ouyang Z, Szucs MJ, et al. Anti-apoptotic Protein BIRC5 Maintains Survival of HIV-1-Infected CD4(+) T Cells. Immunity. 2018;48(6):1183-1194 e1185. PMCID: PMC6013384

38. Jolly C, Mitar I, Sattentau QJ. Adhesion molecule interactions facilitate human immunodeficiency virus type 1 -induced virological synapse formation between T cells. $J$ Virol. 2007;81(24):13916-13921. PMCID: PMC2168851

39. Berlin C, Berg EL, Briskin MJ, Andrew DP, Kilshaw PJ, Holzmann B, Weissman IL, et al. Alpha 4 beta 7 integrin mediates lymphocyte binding to the mucosal vascular addressin MAdCAM-1. Cell. 1993;74(1):185-195.

40. Davila SJ, Olive AJ, Starnbach MN. Integrin alpha4beta1 is necessary for CD4+ T cellmediated protection against genital Chlamydia trachomatis infection. J Immunol. 2014;192(9):4284-4293. PMCID: PMC3995848

41. Campbell GR, Spector SA. CCL2 increases X4-tropic HIV-1 entry into resting CD4+ T cells. J Biol Chem. 2008;283(45):30745-30753. PMCID: PMC2576528

42. Hsiao F, Frouard J, Gramatica A, Xie G, Telwatte S, Lee GQ, Roychoudhury P, et al. Tissue memory CD4+ T cells expressing IL-7 receptor-alpha (CD127) preferentially support latent HIV-1 infection. PLoS Pathog. 2020;16(4):e1008450. PMCID: PMC7192375

43. Lassen KG, Hebbeler AM, Bhattacharyya D, Lobritz MA, Greene WC. A flexible model of HIV-1 latency permitting evaluation of many primary CD4 T-cell reservoirs. PLoS One. 2012;7(1):e30176. PMCID: PMC3265466

44. Lavender KJ, Pace C, Sutter K, Messer RJ, Pouncey DL, Cummins NW, Natesampillai S, et al. An advanced BLT-humanized mouse model for extended HIV-1 cure studies. AIDS. 2018;32(1):1-10. PMCID: PMC5718929 
45. Lavender KJ, Pang WW, Messer RJ, Duley AK, Race B, Phillips K, Scott D, et al. BLThumanized C57BL/6 Rag2-/-gammac-/-CD47-/- mice are resistant to GVHD and develop B- and T-cell immunity to HIV infection. Blood. 2013;122(25):4013-4020. PMCID: PMC3862274

46. Feng Y, Broder CC, Kennedy PE, Berger EA. HIV-1 entry cofactor: functional cDNA cloning of a seven-transmembrane, $G$ protein-coupled receptor. Science. 1996;272(5263):872-877.

47. Dragic T, Litwin V, Allaway GP, Martin SR, Huang Y, Nagashima KA, Cayanan C, et al. HIV-1 entry into CD4+ cells is mediated by the chemokine receptor CC-CKR-5. Nature. 1996;381(6584):667-673.

48. Cocchi F, DeVico AL, Garzino-Demo A, Arya SK, Gallo RC, Lusso P. Identification of RANTES, MIP-1 alpha, and MIP-1 beta as the major HIV-suppressive factors produced by CD8+ T cells. Science. 1995;270(5243):1811-1815.

49. Yadav A, Saini V, Arora S. MCP-1: chemoattractant with a role beyond immunity: a review. Clin Chim Acta. 2010;411(21-22):1570-1579.

50. Doitsh G, Greene WC. Dissecting How CD4 T Cells Are Lost During HIV Infection. Cell

51. Martin N, Sattentau Q. Cell-to-cell HIV-1 spread and its implications for immune evasion. Curr Opin HIV AIDS. 2009;4(2):143-149.

52. Bruno R, Galastri S, Sacchi P, Cima S, Caligiuri A, DeFranco R, Milani S, et al. gp120 modulates the biology of human hepatic stellate cells: a link between HIV infection and liver fibrogenesis. Gut. 2010;59(4):513-520.

53. Del Corno M, Gauzzi MC, Penna G, Belardelli F, Adorini L, Gessani S. Human immunodeficiency virus type $1 \mathrm{gp} 120$ and other activation stimuli are highly effective in triggering alpha interferon and CC chemokine production in circulating plasmacytoid but not myeloid dendritic cells. J Virol. 2005;79(19):12597-12601. PMCID: PMC1211530

54. Kapasi A, Bhat P, Singhal PC. Tubular cell and HIV-1 gp120 interaction products promote migration of monocytes. Inflammation. 1998;22(2):137-144.

55. Conant K, Garzino-Demo A, Nath A, McArthur JC, Halliday W, Power C, Gallo RC, et al. Induction of monocyte chemoattractant protein-1 in HIV-1 Tat-stimulated astrocytes and elevation in AIDS dementia. Proc Natl Acad Sci U S A. 1998;95(6):3117-3121. PMCID: PMC19704

56. Huang W, Rha GB, Han MJ, Eum SY, Andras IE, Zhong Y, Hennig B, et al. PPARalpha and PPARgamma effectively protect against HIV-induced inflammatory responses in brain endothelial cells. J Neurochem. 2008;107(2):497-509. PMCID: PMC2597373

57. Weiss JM, Nath A, Major EO, Berman JW. HIV-1 Tat induces monocyte chemoattractant protein-1-mediated monocyte transmigration across a model of the human blood-brain barrier and up-regulates CCR5 expression on human monocytes. J Immunol. 1999;163(5):2953-2959. expression in astrocytes in a myristoylation- and calmodulin-dependent manner. $J$ Cell Sci. 2006;119(Pt 21):4520-4530. 
59. Marini E, Tiberio L, Caracciolo S, Tosti G, Guzman CA, Schiaffonati L, Fiorentini S, et al. HIV-1 matrix protein 17 binds to monocytes and selectively stimulates MCP-1 secretion: role of transcriptional factor AP-1. Cell Microbiol. 2008;10(3):655-666. PMCID: PMC7162350

60. Lawhorn C, Yuferov V, Randesi M, Ho A, Morgello S, Kreek MJ, Levran O. Genetic diversity and linkage disequilibrium in the chemokine receptor CCR2-CCR5 region among individuals and populations. Cytokine. 2013;64(2):571-576. PMCID: PMC3806048

61. Vazquez-Salat N, Yuhki N, Beck T, O'Brien SJ, Murphy WJ. Gene conversion between mammalian CCR2 and CCR5 chemokine receptor genes: a potential mechanism for receptor dimerization. Genomics. 2007;90(2):213-224.

62. Kim MB, Giesler KE, Tahirovic YA, Truax VM, Liotta DC, Wilson LJ. CCR5 receptor antagonists in preclinical to phase II clinical development for treatment of HIV. Expert Opin Investig Drugs. 2016;25(12):1377-1392. PMCID: PMC5776690

63. Denucci CC, Mitchell JS, Shimizu Y. Integrin function in T-cell homing to lymphoid and nonlymphoid sites: getting there and staying there. Crit Rev Immunol. 2009;29(2):87-109. PMCID: PMC2744463

64. Connor SJ, Paraskevopoulos N, Newman R, Cuan N, Hampartzoumian T, Lloyd AR, Grimm MC. CCR2 expressing CD4+ T lymphocytes are preferentially recruited to the ileum in Crohn's disease. Gut. 2004;53(9):1287-1294. PMCID: PMC1774196

65. Sutter K, Lavender KJ, Messer RJ, Widera M, Williams K, Race B, Hasenkrug KJ, et al. Concurrent administration of IFNalpha14 and cART in TKO-BLT mice enhances suppression of HIV-1 viremia but does not eliminate the latent reservoir. Sci Rep. 2019;9(1):18089. PMCID: PMC6889145

66. Hunt PW, Martin JN, Sinclair E, Bredt B, Hagos E, Lampiris H, Deeks SG. T cell activation is associated with lower CD4+ T cell gains in human immunodeficiency virus-infected patients with sustained viral suppression during antiretroviral therapy. $J$ Infect Dis. 2003;187(10):1534-1543.

67. Hultquist JF, Schumann K, Woo JM, Manganaro L, McGregor MJ, Doudna J, Simon V, et al. A Cas9 Ribonucleoprotein Platform for Functional Genetic Studies of HIV-Host Interactions in Primary Human T Cells. Cell Rep. 2016;17(5):1438-1452. PMCID: PMC5123761

68. Cavrois M, Banerjee T, Mukherjee G, Raman N, Hussien R, Rodriguez BA, Vasquez J, et al. Mass Cytometric Analysis of HIV Entry, Replication, and Remodeling in Tissue CD4+ T Cells. Cell Rep. 2017;20(4):984-998. PMCID: PMC5560086

69. Butler SL, Hansen MS, Bushman FD. A quantitative assay for HIV DNA integration in vivo. Nat Med. 2001;7(5):631-634.

70. O'Doherty U, Swiggard WJ, Jeyakumar D, McGain D, Malim MH. A sensitive, quantitative assay for human immunodeficiency virus type 1 integration. J Virol. 2002;76(21):1094210950. PMCID: PMC136638

71. Vandergeeten C, Fromentin R, Merlini E, Lawani MB, DaFonseca S, Bakeman W, McNulty $A$, et al. Cross-clade ultrasensitive PCR-based assays to measure HIV persistence in large-cohort studies. J Virol. 2014;88(21):12385-12396. PMCID: PMC4248919 
bioRxiv preprint doi: https://doi.org/10.1101/2021.02 25.432826; this version posted February 25, 2021. The copyright holder for this preprint

(which was not certified by peer review) is the author/funder, who has granted bioRxiv a license to display the preprint in perpetuity. It is made available under aCC-BY 4.0 International license.

72. Widera M, Dirks M, Bleekmann B, Jablonka R, Daumer M, Walter H, Ehret R, et al. HIV-1 persistent viremia is frequently followed by episodes of low-level viremia. Med Microbiol Immunol. 2017;206(3):203-215. PMCID: PMC5409919 
FIGURES \& LEGENDS
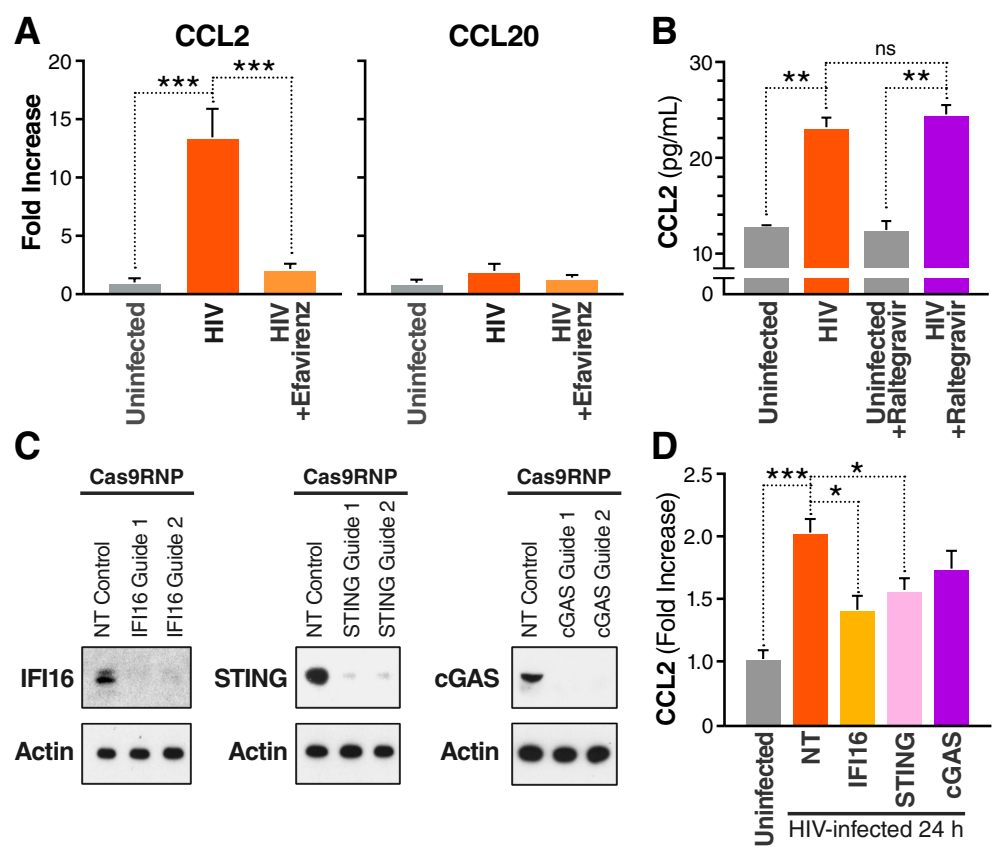

Figure 1: Tonsil CD4 T cells produce CCL2 following HIV infection in part mediated through IFI16 and STING signaling. Tonsil CD4 T cells were purified by negative bead selection and infected with HIV by overlay infection as previously described ${ }^{21}$. (A) Production of CCL2 and CCL20 RNA was measured by qPCR and plotted as fold increase relative to uninfected controls following 18 hours of overlay infection. Treatment with efavirenz (a non-nucleoside reverse transcriptase inhibitor) blocked induction of CCL2. (B) CCL2 protein secretion measured by Meso Scale Discovery (MSD) was detected following 24 hours of overlay HIV infection of tonsil CD4 cells. Addition of raltegravir (an HIV integrase inhibitor) did not block production of CCL2. (C) Cas9RNPs and two independent guide RNAs (gRNAs) were used to knockout IFI16, STING and cGAS protein expression in primary tonsil CD4 T cells (NT: non-targeting gRNA control). (D) CCL2 protein production was significantly diminished (but not eliminated) in HIV-infected cultures when IFI16 or STING were knocked out. Supernatants were harvested 24 hours after infection for MSD analysis of CCL2 production. Fold increase versus uninfected control is shown for each knockout culture. Experiments were performed with 4-6 independent tonsils. Error bars denote SEM; ANOVA with Tukey's multiple comparisons, ${ }^{*} p<0.05,{ }^{* *} p<0.01,{ }^{* *} p<0.001$. 

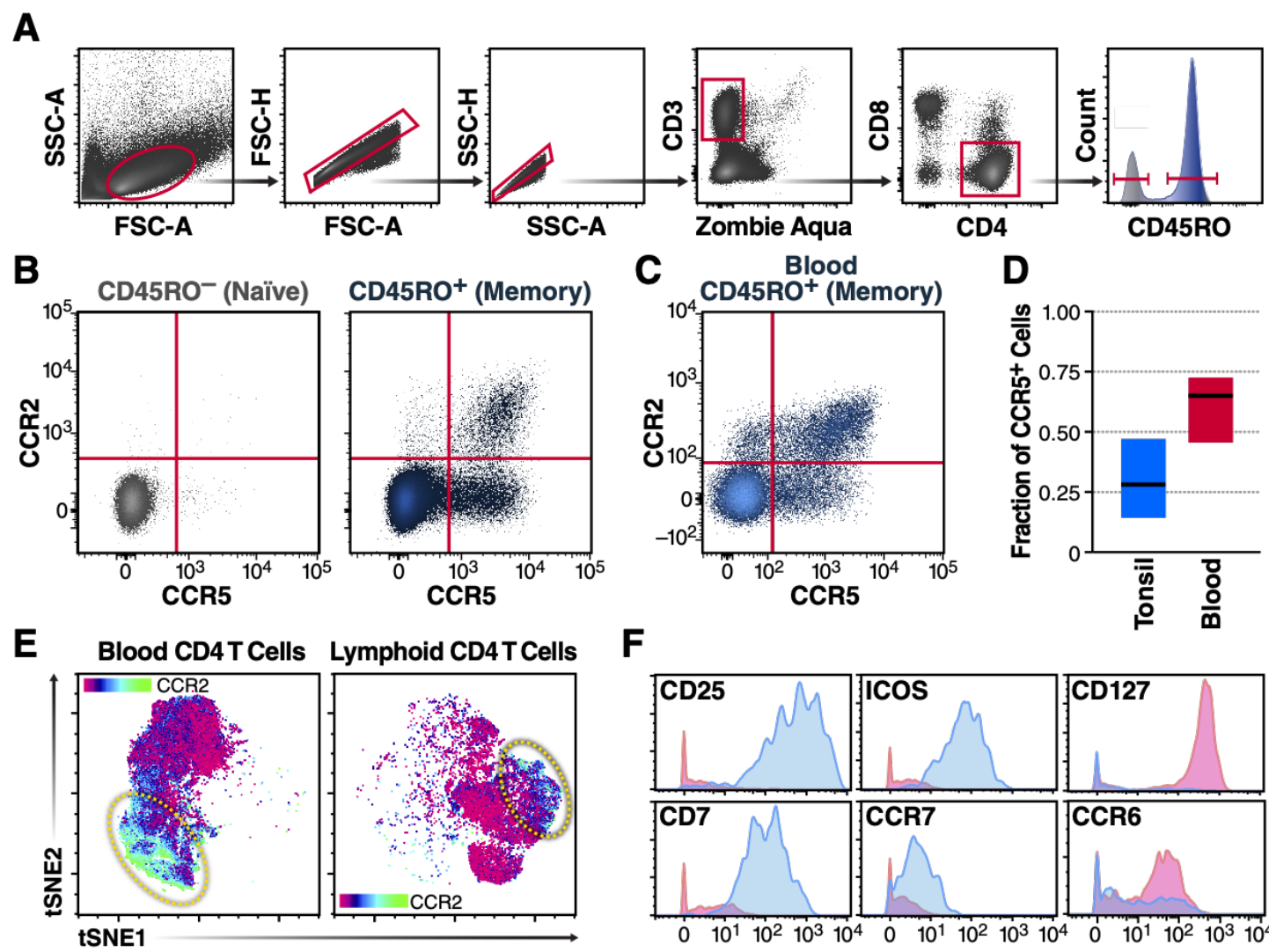

D

$\mathbf{F}$
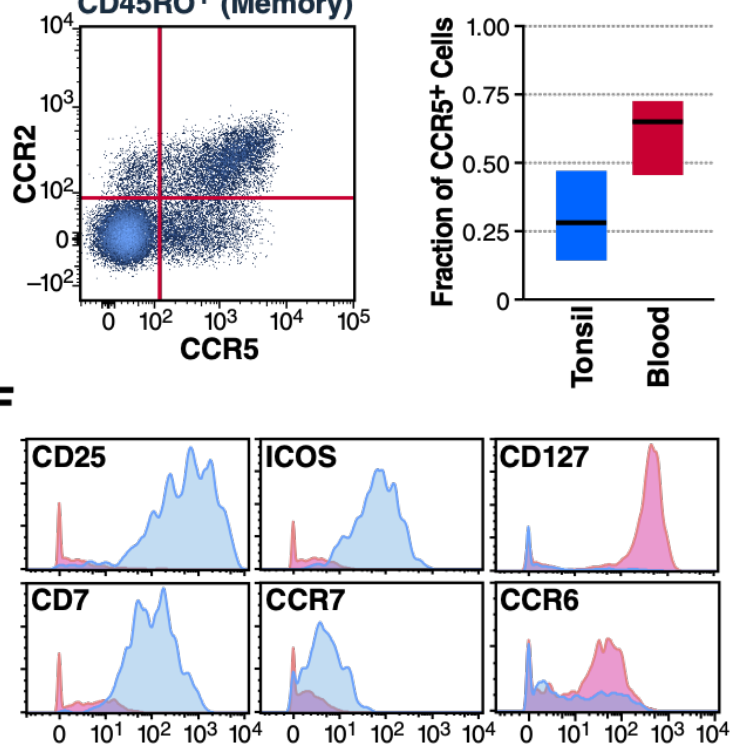

Figure 2: CCR2/5+ CD4 T cells in the lymphoid tissue exhibit a distinct phenotype compared to their cellular counterparts circulating in blood. Freshly isolated mononuclear cells from tonsil and blood were analyzed by multicolor flow cytometry. (A) Gating strategy for tonsil memory CD4 T cells is presented. (B) CCR2+ expression is primarily limited to CCR5+ memory T cells in tonsil (gated as in panel A). (C) Representative chemokine receptor expression of blood-derived memory cells. (D) CCR2+ is expressed on a significant fraction of CCR5+ memory CD4 T cells: $28 \% \pm 11 \%$ in tonsil $(n=18)$ and $65 \% \pm 10 \%$ in blood $(n=8)$. (E) Mass cytometry was used to compare blood-derived and lymphoid tissue-derived CD4 cells across 38 different parameters, and tSNE dimensional reduction visualization was performed $(n=10$ for tonsil and blood). Shown are representative tSNE plots, colored by surface CCR2 expression. (F) Selected markers highlight differences between lymphoid tissue (blue) and blood-derived (red) CCR2/5+ cells (See Figure 2-figure supplement 2 for further comparisons). 
A
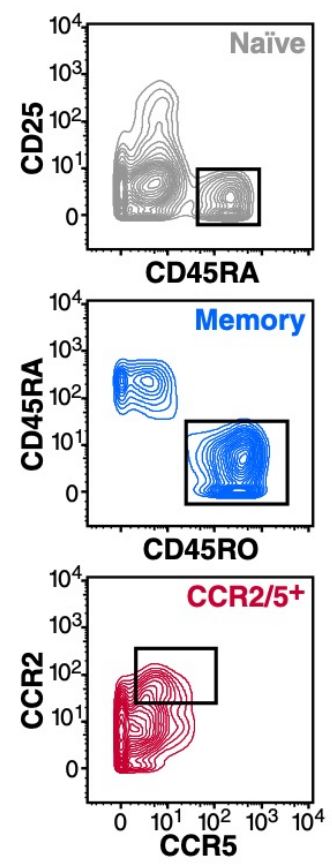

B
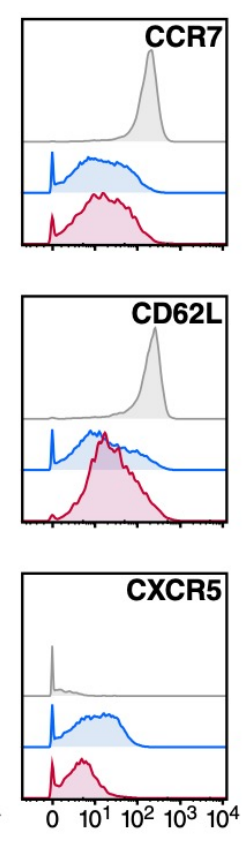

Activation Markers
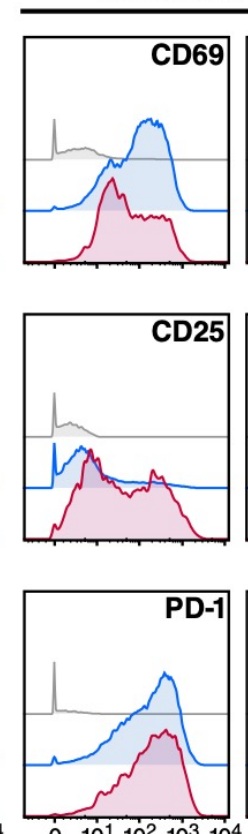

$010^{1} 10^{2} 10^{3} 10^{4}$
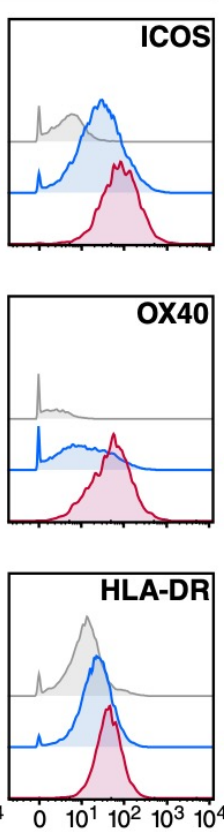

Synapse
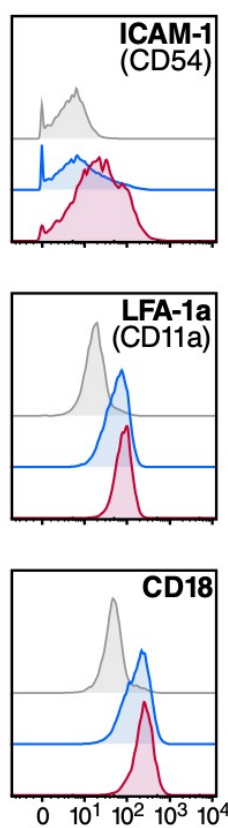

Migration
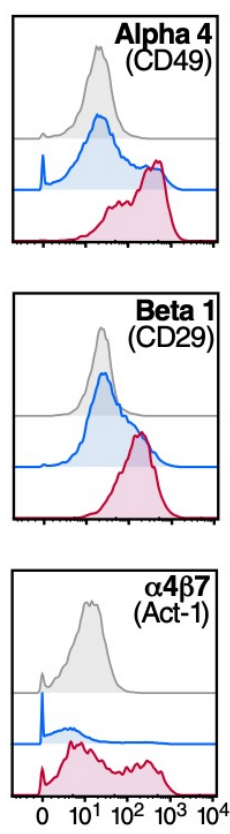

Figure 3: Tonsil CCR2/5+ cells express markers of central memory, activation, viral synapse, and tissue homing. Freshly isolated CD4 T cells from tonsil were analyzed for expression of 38 surface markers by mass cytometry. (A) Gating strategy for naïve (pre-gated on CD3+, CD4+, CD8-, CD45RO-, live single cells), memory (pre-gated on CD3+, CD4+, CD8- live single cells), and CCR2/5+ CD4 T cells (pre-gated on memory as above); data shown from representative tonsil $(n=10)$. (B) Comparison of marker expression between populations gated as in A (top gray trace, naïve; middle blue trace, memory; bottom pink trace, CCR2/5+). 


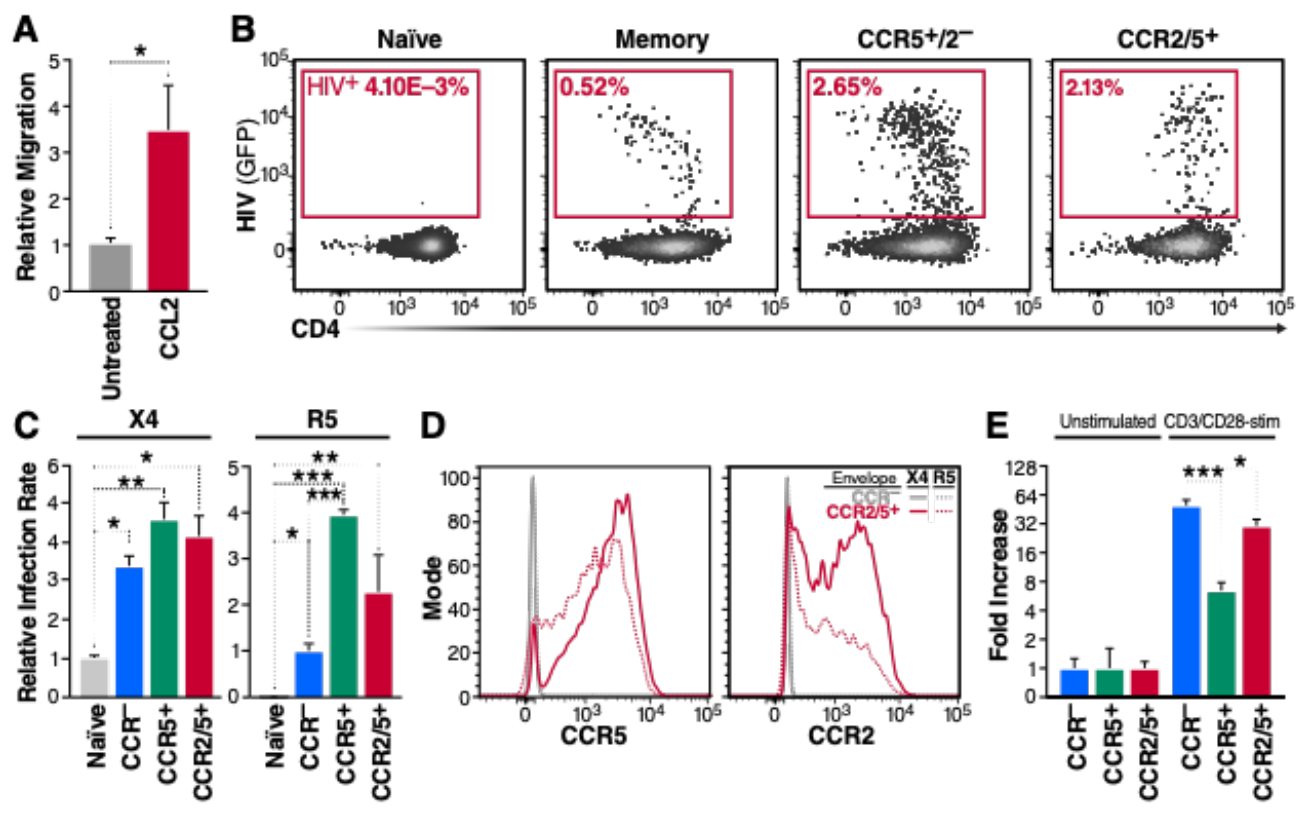

Figure 4: Tonsil CCR2/5+ T cells are permissive to X4- and R5-tropic HIV infection. (A) Transwell migration assay of purified tonsil CD4 cells added to the upper chamber of a $2 \mu \mathrm{m}$ transwell membrane, with $2 \mathrm{ng} / \mathrm{mL}$ CCL2 added to the bottom chamber. After 4 hours, the migrating cells (collected from the bottom chamber) were analyzed by flow cytometry and counted. Data are presented as a relative migration (fold increase of chemokine receptor positive over negative cell migration normalized to untreated control). (B) Assessment of HIV infection in naïve, memory (chemokine receptor negative), CCR5+, or CCR2/5+ CD4 T cells after sort purification and infection with 100 ng GFP-reporter BaL.NL4-3 HIV-1 (R5-tropic). GFP expression denotes productive infection. (C) Relative percentage of GFP-positive cells as gated in panel B, including NL4-3 HIV-1 (X4-tropic) for comparison ( $n=4)$. (D) R5-tropic envelope causes loss of surface CCR2. CCR5 and CCR2 levels of sorted CCR-negative memory (gray) or CCR2/5+ cells (pink) spinoculated with X4- (solid lines) or R5-tropic (dotted lines) HIV and cultured for 24 hours (E) To assess the ability of tonsil CCR2/5+ cells to support latent infection, a previously described primary CD4 T cell latency model was employed ${ }^{43}$. Cells sorted as in panel B were spinoculated with NL4-3-luciferase reporter virus and cultured in the presence of ART for 5 days. Cells were then reactivated with anti-CD3/28 beads for 24 hours. Virus production after reactivation was measured by quantitating luciferase activity. Data are presented as fold increases in stimulated cells relative to unstimulated cells. Experiments involved the analysis of 4-8 independent tonsil preparations. Error bars denote SEM; ANOVA with Tukey's multiple comparisons, * $p<0.05$, ${ }^{* *}$ $p<0.01,{ }^{* *} p<0.001$. 

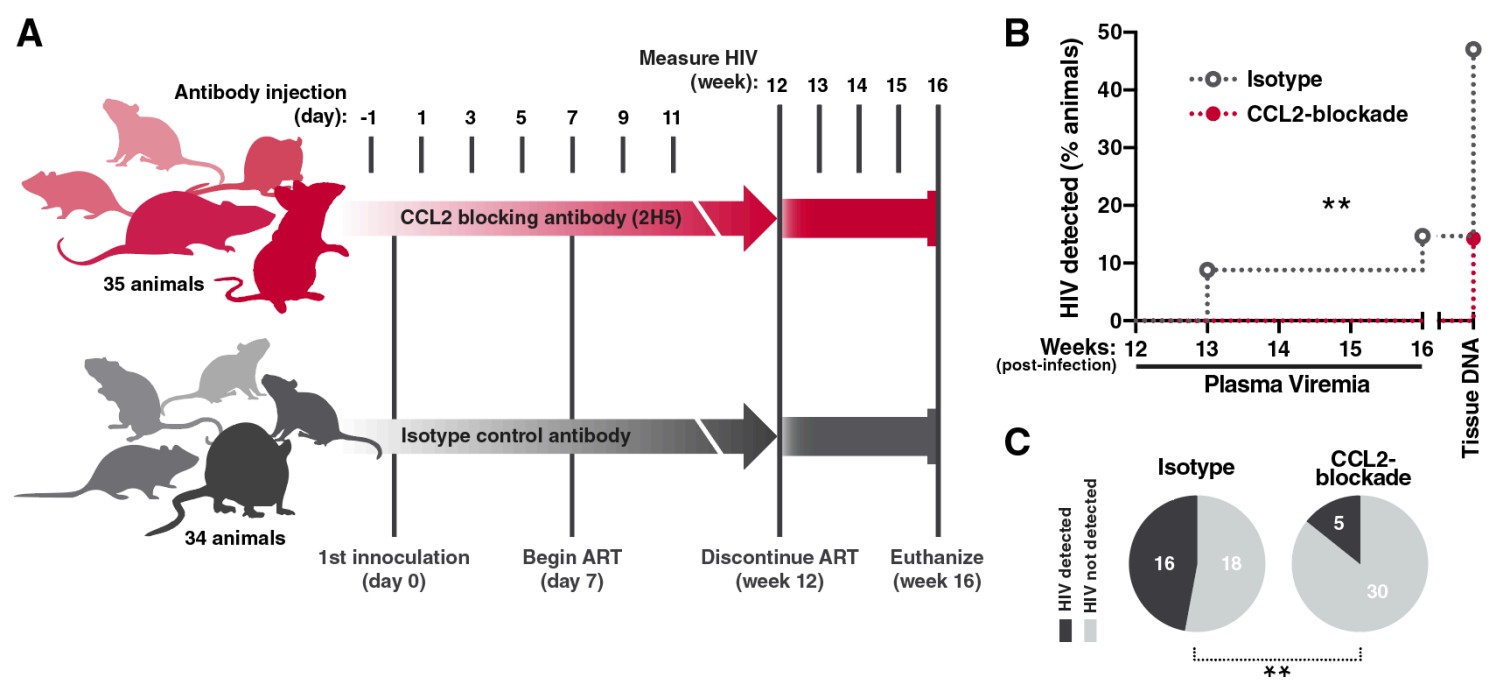

Figure 5: Blockade of CCL2 reduces seeding of the HIV reservoir in humanized mice. (A) Humanized mice were injected with $200 \mu \mathrm{g}$ CCL2-blocking antibody (2H5) or isotype control beginning at 24 hours pre-infection, followed by $100 \mu \mathrm{g}$ re-administered every 48 hours for a total of 12 days. Mice were challenged with HIV intrarectally at day 0 every 24 hours for 5 days and at day 7 were administered ART orally (chow infused). ART was maintained for 11 weeks and discontinued at week 12. Mice were bled weekly following ART-interruption and euthanized at week 16 post-infection. (B) HIV plasma RNA was quantified following ART-interruption and HIV DNA was measured in the spleen following euthanasia. CCL2-blockade decreased the detection of HIV (Log-rank test $=0.002$ ) and $(\mathbf{C})$ overall frequency of animals with detectable HIV (Fisher exact $=0.0041)$. Cumulative data shown from two independent experiments. 
A
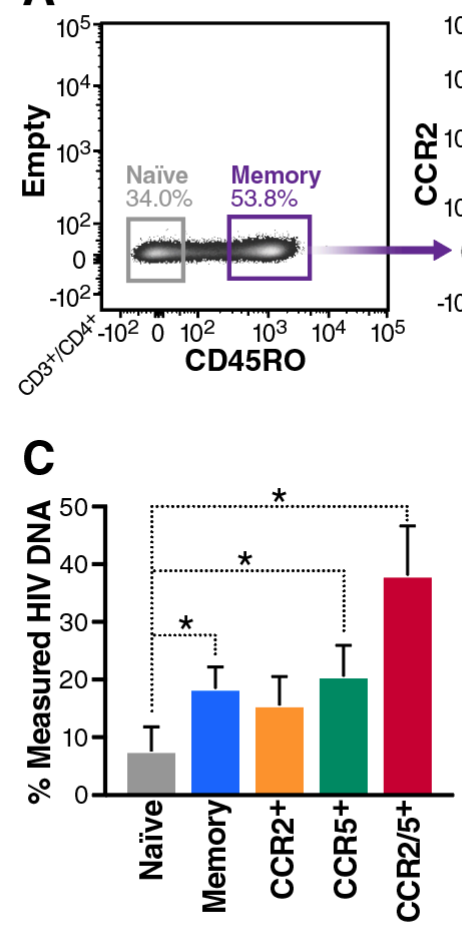

B

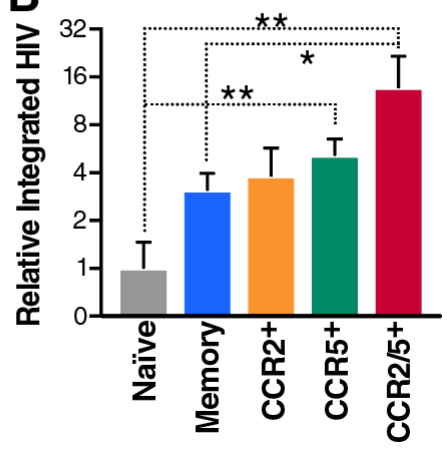

D
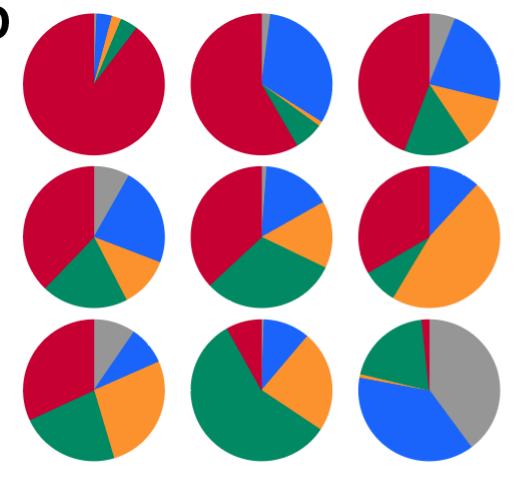

CCR2/5+

CCR5+

CCR2+

Memory

Naïve

Figure 6: Integrated HIV proviral DNA is enriched in CCR2/5+ cells. Naïve, Memory (CCR-), CCR2+, CCR5+, or CCR2/5+ CD4 T cells were purified by cell sorting from leukapheresis samples obtained from ART-suppressed, HIV-infected donors. (A) Example of sorting gates from donor cells, pre-gated on live, single CD3+, CD4+ cells. (B) Amount of integrated HIV in sorted cell populations, normalized to mitochondrial DNA and expressed as fold increase over the amount detected in naïve cells. Cells were sorted as in panel A, genomic DNA was isolated, and provirus was measured using ALU-gag droplet digital PCR. (C and D) Distribution of HIV provirus among various cell populations from nine ART-suppressed HIV-infected donors. Results are shown as a percentage of total HIV detected from all subsets for each individual $(n=9)$. Results are grouped by cell type in panel $\mathrm{C}$ and separated by individual in panel $\mathrm{D}$. Error bars denote SEM, Friedman ANOVA with Dunn's test for multiple comparisons, ${ }^{*} p<0.05,{ }^{* *} p<0.01$. 


\section{SUPPLEMENTAL FIGURES}

\section{Figure Supplement 1}
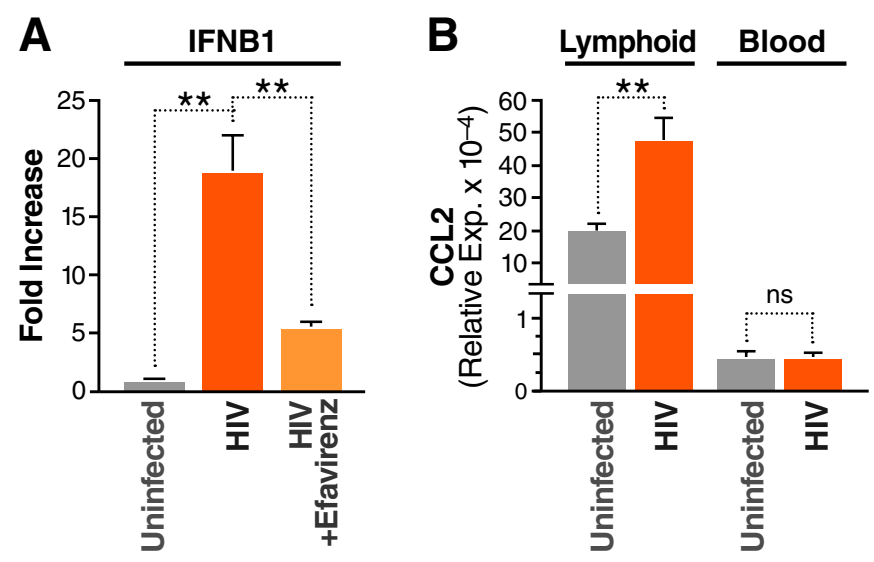

Figure Supplement 1: Cytokine responses to HIV by purified CD4 T cells. (A) Type 1 interferon is rapidly induced by lymphoid tissue CD4 T cells following HIV infection. Tonsillar CD4 T cells were purified by negative bead selection and infected with HIV by overlay infection for 18 hours ${ }^{21}$. Production of IFNB1 RNA was measured by qPCR and plotted as fold increase relative to uninfected control. Treatment with efavirenz during overlay infection blocked induction of IFNB1. (B) CD4 T cells purified from PBMCs do not produce CCL2 in response to HIV. CD4 T cells were purified by negative bead selection from healthy donor PBMCs or tonsils and infected with HIV by overlay infection for 32 hours. Additionally, lymphoid tissue-derived CD4 T cells express substantially more CCL2 transcripts at baseline than PBMC T cells. Shown as level relative to housekeeping genes (geometric mean of GAPDH and 18S RNA). Experiments included 2-3 tonsil donors and were repeated at least twice. Error bars denote SEM ( ${ }^{*} p<0.05$, $\left.{ }^{\star *} p<0.01\right)$. 
Figure Supplement 2
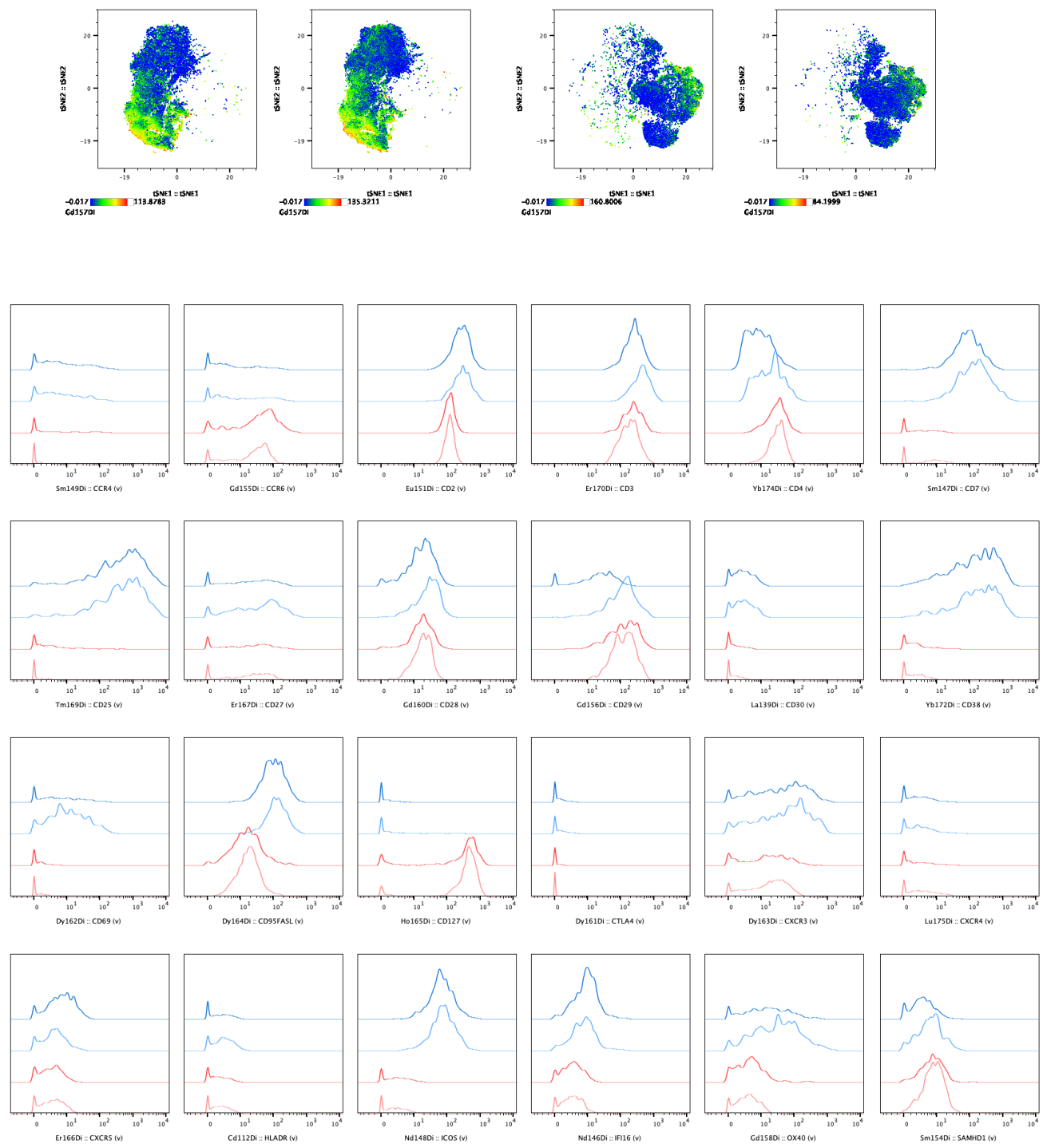

Figure Supplement 2: Comparison of blood and lymphoid tissue CCR2/5+ cells by mass cytometry. Fresh mononuclear cells were isolated from healthy donor PBMCs or tonsils and analyzed for expression of 38 markers by mass cytometry ( $n=10$ donors of each tissue). (Top) tSNE dimensional reduction visualization was performed, colored by surface CCR2 expression. (Bottom) Cells were gated for CCR2/5 expression as in Figure 2. Shown here are a panel of markers which were different or similar between lymphoid tissue (blue) and blood-derived (red) CCR2/5+ cells. 


\section{Figure Supplement 3}

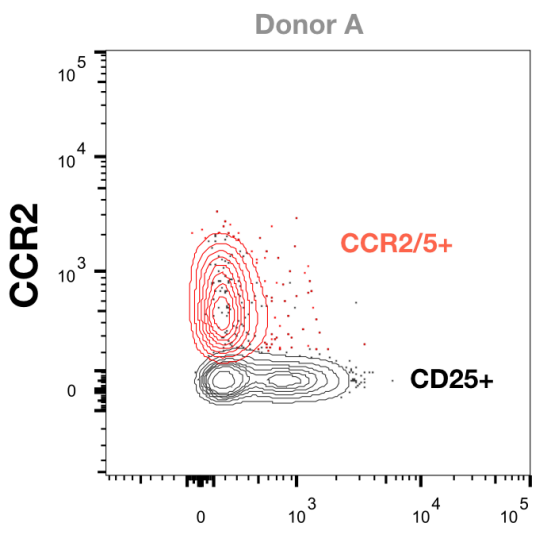

FoxP3

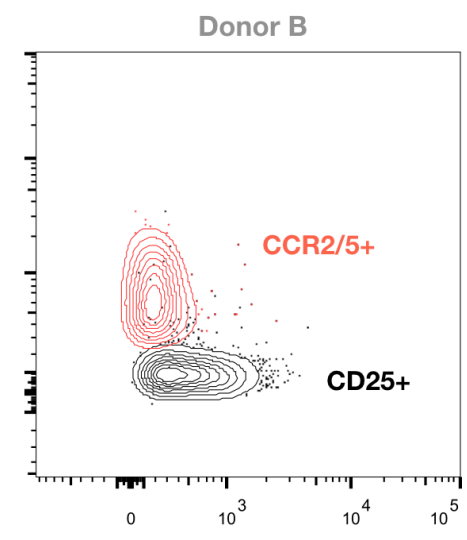

FoxP3

Figure Supplement 3: CCR2/5+ cells lack FoxP3 expression. CD4 T cells were purified by negative bead selection from two healthy donor PBMCs and surface stained, then fixed and permeabilized using FoxP3 Fix/Perm kit (eBiosciences) per the manufacturer's protocol. Cells are gated on live singlets, CD3+, CD8-, CD4+, CD45RO+, and CD25+ (red) or CCR2/5+ (black). 
Figure Supplement 4
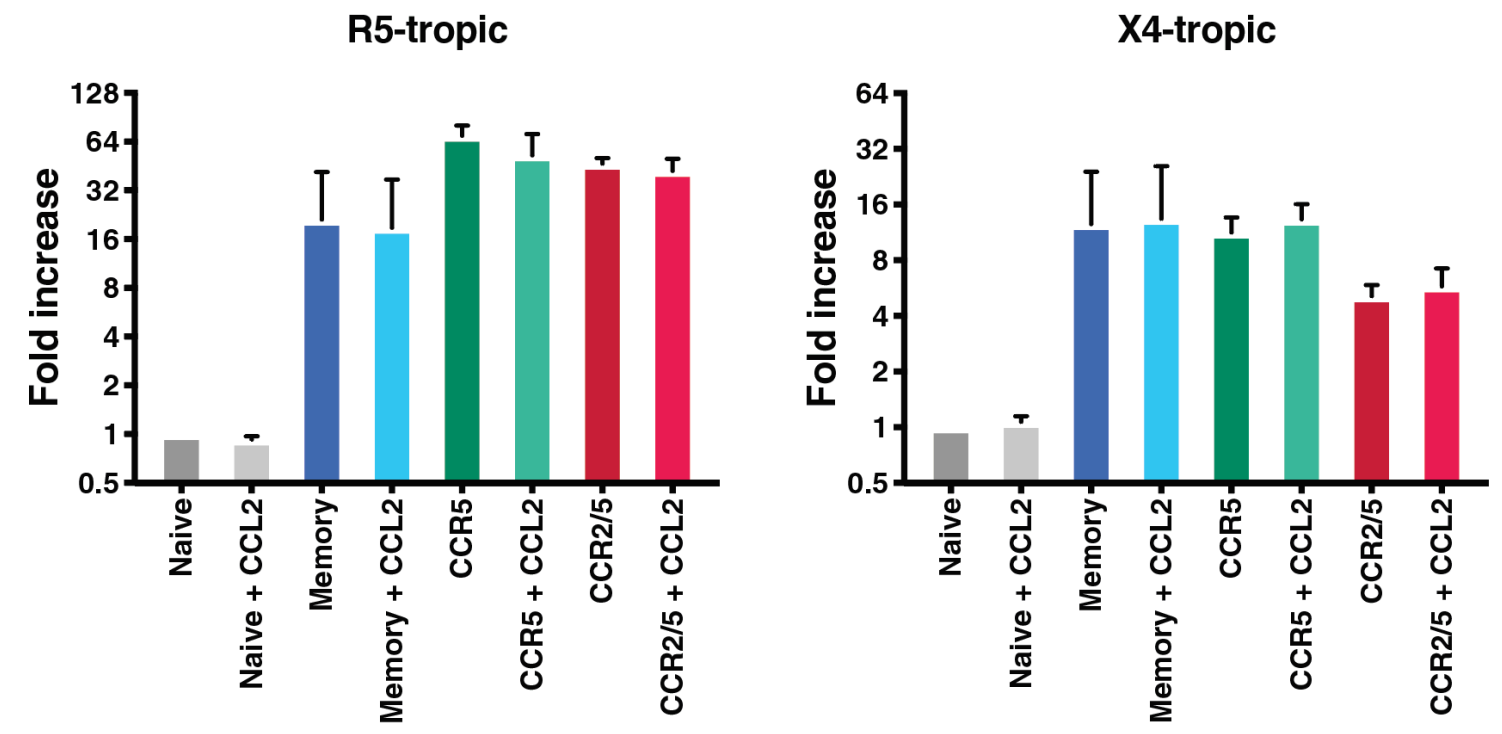

Figure Supplement 4: Addition of CCL2 does not enhance HIV infection in lymphoid tissue CD4 T cells. To test the effect of CCL2 signaling on HIV infection, cells were sorted from healthy tonsils as in Figure 4, and spinoculated with 100 ng GFP-reporter NL4-3 HIV-1 (X4-tropic) or BaL.NL4-3 HIV-1 (R5-tropic) followed by culture with or without CCL2 (5 $\mu \mathrm{g} / \mathrm{mL})$ (Peprotech). 48 hours later, levels of infection were measured by flow cytometric assessment of GFP+ cells and compared to infection levels in naïve cells. No significant differences in infection were observed in any of the cell populations treated with CCL2. Experiments included 2 tonsil donors and were repeated twice.

Figure Supplement 5
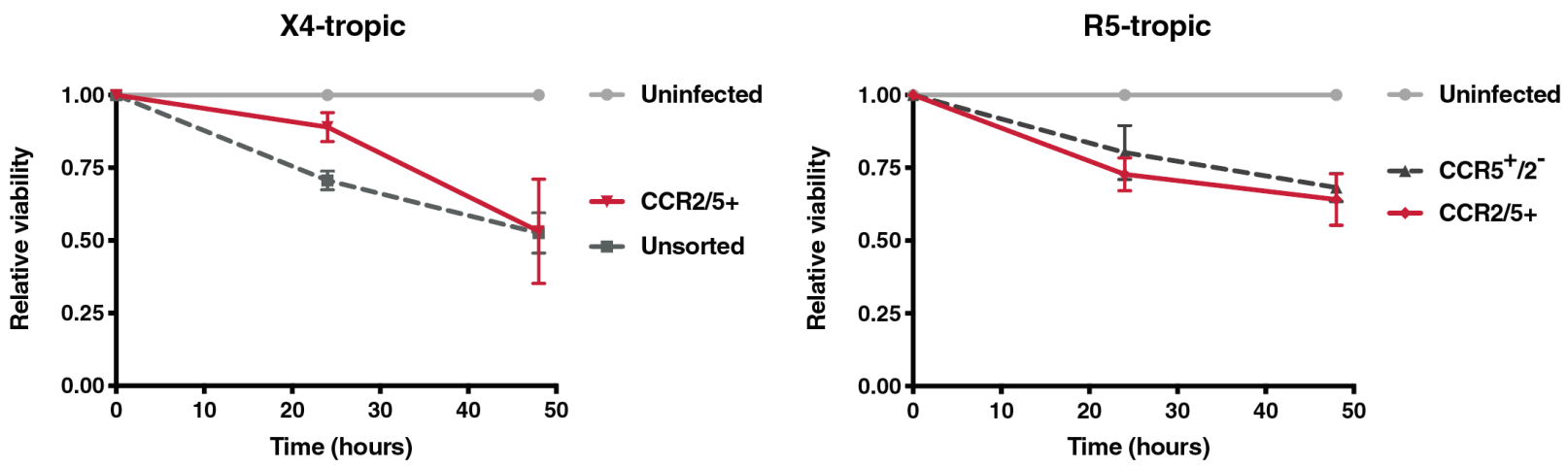

Figure Supplement 5: CCR2/5+ cells succumb to HIV infection at a similar rate as CCR5+ cells. To measure the susceptibility of CCR2/5+ cells to cell death following HIV infection, CD4 T cells were sorted and overlay infected with $50 \mathrm{ng}$ NL4-3 HIV-1 (X4-tropic) or BaL.NL4-3 HIV-1 (R5-tropic), and live cells were quantified by normalizing to fluorescent beads at 24 and 48 hours post-infection. Experiments included 2 tonsil donors and were repeated twice. 
Table Supplement 1

Mass Cytometry Panel

\begin{tabular}{|c|c|c|c|}
\hline Target & Metal & Clone & Vendor \\
\hline HLADR & Cd112Di & TÜ36 & $\begin{array}{c}\text { Life } \\
\text { Technologies }\end{array}$ \\
\hline Livedead1 & In113Di & $\begin{array}{l}\text { N/A (In- } \\
\text { DOTA } \\
\text { maleimide) }\end{array}$ & Sigma-Aldrich \\
\hline Livedead2 & In115Di & $\begin{array}{c}\text { N/A (In- } \\
\text { DOTA } \\
\text { maleimide) }\end{array}$ & Sigma-Aldrich \\
\hline CD161 & La139Di & HP-3G10 & In-house \\
\hline Bead1 & Ce140Di & $\mathrm{N} / \mathrm{A}$ & Fluidigm \\
\hline CD49d & Pr141Di & 9F10 & Fluidigm \\
\hline CD11a & Nd142Di & HI111 & Fluidigm \\
\hline CD57 & Nd143Di & HCD57 & In-house \\
\hline CCR5 & Nd144Di & NP-6G4 & Fluidigm \\
\hline CD31 & Nd145Di & WM59 & Fluidigm \\
\hline CD8 & Nd146Di & RPA-T8 & Fluidigm \\
\hline CD7 & Sm147Di & CD7-6B7 & Fluidigm \\
\hline CD19 & Nd148Di & HIB19 & In-house \\
\hline CCR4 & Sm149Di & 205410 & Fluidigm \\
\hline $\begin{array}{c}\mathrm{HSA} \\
\text { (mouse) }\end{array}$ & Nd150Di & M1/69 & Fluidigm \\
\hline ICOS & Eu151Di & DX29 & Fluidigm \\
\hline CCR10 & Sm152Di & 1B5 & In-house \\
\hline CD62L & Eu153Di & DREG-56 & Fluidigm \\
\hline CD3 & Sm154Di & UCKT1 & Fluidigm \\
\hline CCR6 & Gd155Di & $11 \mathrm{~A} 9$ & In-house \\
\hline CD29b1 & Gd156Di & TS2/16 & Fluidigm \\
\hline CCR2 & Gd157Di & K036C2 & In-house \\
\hline OX40 & Gd158Di & ACT35 & Fluidigm \\
\hline CD90 & Tb159Di & 5E10 & Fluidigm \\
\hline CD28 & Gd160Di & CD28.2 & Fluidigm \\
\hline CD45RO & Dy161Di & UCHL1 & In-house \\
\hline CD69 & Dy162Di & FN50 & Fluidigm \\
\hline CXCR3 & Dy163Di & G025H7 & Fluidigm \\
\hline PD-1 & Dy164Di & EH12.1 & In-house \\
\hline CD127 & Ho165Di & A019D5 & Fluidigm \\
\hline CCR7 & Er166Di & 150503 & In-house \\
\hline CD27 & Er167Di & L128 & Fluidigm \\
\hline CD18 & Er168Di & TS1/18 & In-house \\
\hline CD45RA & Tm169Di & HI100 & Fluidigm \\
\hline CD54 & Er170Di & HA58 & Fluidigm \\
\hline CXCR5 & Yb171Di & 51505 & Fluidigm \\
\hline CD38 & Yb172Di & HIT2 & Fluidigm \\
\hline a4b7 & Yb173Di & Act1 & In-house \\
\hline CD4 & Yb174Di & SK3 & Fluidigm \\
\hline CXCR4 & Lu175Di & $12 \mathrm{G5}$ & Fluidigm \\
\hline CD25 & Yb176Di & M-A251 & In-house \\
\hline DNA1 & Ir191Di & N/A & Fluidigm \\
\hline DNA2 & Ir193Di & N/A & Fluidigm \\
\hline
\end{tabular}


Table Supplement 2: Characteristics of HIV-1 infected study participants (Related to Figure 5 and STAR methods). Nine HIV-1-infected individuals, who met the criteria of suppressive ART $(<50$ copies $/ \mathrm{ml})$ for at least of six months, and a CD4+ T cell count of at least $500 \mathrm{cells} / \mathrm{mm}^{3}$ at time of study were enrolled. The participants were recruited from the SCOPE cohorts ${ }^{66}$

\begin{tabular}{|c|c|c|c|c|c|c|}
$\begin{array}{c}\text { Participant } \\
\text { ID }\end{array}$ & Age & Sex & Ethnicity & $\begin{array}{c}\text { CD4 } \\
\text { count } \\
\text { (cells/ul) }\end{array}$ & ART regimen & $\begin{array}{c}\text { ART } \\
\text { start } \\
\text { year }\end{array}$ \\
\hline 1695 & 39 & Female & Mixed & 556 & $\begin{array}{c}\text { FTC/TDF, ATV, } \\
\text { RTV }\end{array}$ & 2010 \\
\hline 2021 & 51 & Male & Black & 540 & RPV/TAF/FTC & 1999 \\
\hline 2146 & 71 & Male & Mixed & 204 & $\begin{array}{c}\text { DRV/COBI, TCV, } \\
\text { DES }\end{array}$ & 1995 \\
\hline 2161 & 68 & Male & White & 687 & $\begin{array}{c}\text { 3TC, RTV, DRV, } \\
\text { TCV }\end{array}$ & 2005 \\
\hline 2168 & 58 & Male & $\begin{array}{c}\text { African } \\
\text { American }\end{array}$ & 246 & ABC/TCV/3TC & 2000 \\
\hline 2375 & 71 & Male & White & 727 & EFV/TDF/FTC & 1995 \\
\hline 2402 & 40 & Male & $\begin{array}{c}\text { African } \\
\text { American }\end{array}$ & 765 & $\begin{array}{c}\text { RTV, DRV, } \\
\text { RPV/TDF/FTC }\end{array}$ & 2006 \\
\hline 2461 & 63 & Male & White & 496 & TCV, RPV & 1999 \\
\hline 2511 & 48 & Male & White & 334 & $\begin{array}{c}\text { EFV/TDF/FTC, } \\
\text { RGV }\end{array}$ & 2010 \\
\hline
\end{tabular}

3TC, lamivudine; ABC, abacavir; ATV, atazanavir; COBI, cobicistat; DRV, darunavir; ETV, etravirine; FTC, emtricitabine; RGV, raltegravir; RPV, rilpivirine; RTV, ritonavir; TDF, tenofovir; TCV, tivicay.

\section{KEY RESOURCES TABLE}

\begin{tabular}{|l|l|l|}
\hline REAGENT or RESOURCE & SOURCE & IDENTIFIER \\
\hline Antibodies & & \\
\hline APC/Cy7 anti-human CD3 [SK7] & Biolegend & 344818 \\
\hline PE/Cy7 anti-human CD4 [A161A1] & Biolegend & 357410 \\
\hline PE anti-human CD8a [HIT8a] & Biolegend & 300908 \\
\hline APC anti-human CD19 [HIB19] & Biolegend & 302212 \\
\hline $\begin{array}{l}\text { Alexa Fluor 388 anti-human anti-human FoxP3 } \\
\text { [206D] }\end{array}$ & Biolegend & 320111 \\
\hline APC anti-human CD25 [BC96] & & \\
\hline PerCP/Cy5.5 anti-human CD45RO [UCHL1] & Biolegend & 302610 \\
\hline BV421 anti-human CCR5 [J418F1] & Biolegend & 304222 \\
\hline BV650 anti-human CCR7 [G04387] & Biolegend & 359118 \\
\hline PE/Dazzle 594 anti-human CCR2 [K036C2] & Biolegend & 353234 \\
\hline PE anti-human CCR2 [K036C2] & Biolegend & 357222 \\
\hline APC anti-CD45RA [HI100] & Biolegend & 357206 \\
\hline
\end{tabular}




\begin{tabular}{|c|c|c|}
\hline Mass Cytometry Panel & Fluidgm/In-house & $\begin{array}{l}\text { See Table S1 for } \\
\text { details }\end{array}$ \\
\hline Mouse anti-human IFI16 mAb [1G7] & Santa Cruz & SC-8023 \\
\hline Rabbit anti-human STING mAb [D2P2F] & $\begin{array}{l}\text { Cell Signaling } \\
\text { Technology }\end{array}$ & $13647 S$ \\
\hline Rabbit anti-human cGAS & Sigma-Aldrich & ABF124 \\
\hline HRP-conjugated mouse-anti-human kappa chain & Abcam & $a b 79115$ \\
\hline Armenian Hamster anti-CCL2 (2H5) & BioXCell & BE0185 \\
\hline Armenian Hamster IgG & BioXCell & BE0091 \\
\hline \multicolumn{3}{|l|}{ Bacterial and Virus Strains } \\
\hline NL4-3-GFP HIV-1 & PMID: 21111238 & $\mathrm{~N} / \mathrm{A}$ \\
\hline BaL-GFP HIV-1 & PMID: 28207890 & $\mathrm{~N} / \mathrm{A}$ \\
\hline NL4-3-Luciferase HIV-1 & PMID: 22291913 & $\mathrm{~N} / \mathrm{A}$ \\
\hline One Shot Stbl3 Chemically Competent E. coli cells & Life Technologies & C7373-03 \\
\hline \multicolumn{3}{|l|}{ Biological Samples } \\
\hline Leukapacks from HIV positive individuals & SCOPE cohort & $\begin{array}{l}\text { See Table S2 for } \\
\text { individuals' details }\end{array}$ \\
\hline Blood from Healthy donors & Vitalant & Vitalant.org \\
\hline Tonsil and spleen from healthy donors & CHTN & chtn.org \\
\hline \multicolumn{3}{|l|}{ Chemicals, Peptides, and Recombinant Proteins } \\
\hline Recombinant Human IL-2 Protein & R\&D Systems & 202-IL-010/CF \\
\hline Recombinant Human MCP-1 (CCL2) Protein & Peprotech & $300-04$ \\
\hline Recombinant Cas9 for RNP nucleofection & QB3 Macrolab, UCB & $\begin{array}{l}\text { Anders and Jinek, } \\
2014\end{array}$ \\
\hline P3 Primary Cell 96-well Nucleofector Kit & Lonza & \\
\hline Fugene HD - Transfection Reagent & Promega & E312 \\
\hline $\begin{array}{l}16 \% \text { Paraformaldehyde (formaldehyde) aqueous } \\
\text { solution }\end{array}$ & $\begin{array}{l}\text { Electron Microscopy } \\
\text { Sciences }\end{array}$ & 15710 \\
\hline EDTA, pH 8.0 & Thermo-Fisher & AM9260G \\
\hline RPMI & Fisher Scientific & MT10040CM \\
\hline DMEM & Fisher Scientific & MT10013CM \\
\hline N-acetyl-L-Cysteine & Sigma-Aldrich & A9165 \\
\hline Gibco $^{\mathrm{TM}}$ 2-Mercaptoethanol & Thermo-Fisher & 21985023 \\
\hline FBS & Gemini Bio-Products & $100-106$ \\
\hline PBS & Fisher Scientific & MT21031CV \\
\hline Opti-MEM & Life Technologies & 31985-062 \\
\hline Gentamicin Reagent Solution (10 mg/ml), Liquid & Thermo Fisher & $15710-072$ \\
\hline Ampicillin sodium salt & Sigma-Aldrich & A9518 \\
\hline Sodium pyruvate solution $100 \mathrm{mM}$ & Sigma-Aldrich & S8636 \\
\hline Nonessential amino acids (MEM NEAA) & Life Technologies & $11140-050$ \\
\hline L-Glutamine:Penicillin:Streptomycin Solution & $\begin{array}{l}\text { GEMINI Bio- } \\
\text { products }\end{array}$ & $400-110$ \\
\hline Fungizone Amphotericin B 250UG/mL & Invitrogen & $15290-018$ \\
\hline Zombie Violet Viability Stain & Biolegend & 423114 \\
\hline Zombie Aqua Viability Stain & Biolegend & 423102 \\
\hline Zombie Yellow Viability Stain & Biolegend & 423104 \\
\hline AccuCount counting beads & Spherotech & ACFP-70-10 \\
\hline
\end{tabular}




\begin{tabular}{|c|c|c|}
\hline \multicolumn{3}{|l|}{ Critical Commercial Assays } \\
\hline EasySep direct human CD4+ T cell kit & STEM CELL & 19662 \\
\hline Dynabeads $^{\mathrm{TM}}$ Human T-Activator CD3/CD28 & Thermo Fisher & $1131 \mathrm{D}$ \\
\hline RNeasy Mini Kit & Qiagen & 74104 \\
\hline QIAamp Viral RNA Kit & Qiagen & 52906 \\
\hline QIAamp DNA blood mini kit & Qiagen & 51106 \\
\hline Rotor-Gene Probe PCR Kit & Qiagen & 204374 \\
\hline RealTime HIV-1 m2000 & Abbott & 04N66-090 \\
\hline SuperScript ${ }^{\circledR}$ III First-Strand Synthesis System & Thermo Fisher & 18080051 \\
\hline TaqMan $^{\mathrm{TM}}$ Gene Expression Master Mix & Thermo Fisher & 4369016 \\
\hline CCL2 MSD (V-PLEX Human MCP-1 Kit) & $\begin{array}{l}\text { Meso Scale } \\
\text { Discovery }\end{array}$ & K151NND-1 \\
\hline DNeasy Blood \& Tissue Kit & Qiagen & 69504 \\
\hline ddPCR $^{\text {TM }}$ Supermix for Probes (No dUTP) & Bio Rad & 1863023 \\
\hline Droplet generation oil for probes & Bio-Rad & $186-3005$ \\
\hline One-Step RT-ddPCR Advanced Kit for Probes & Bio-Rad & 1864021 \\
\hline Foxp3/Transcription Factor Staining Buffer Set & Thermo Fisher & $00-523-00$ \\
\hline 1-Step Ultra TMB ELISA & Thermo Fisher & 34208 \\
\hline \multicolumn{3}{|l|}{ Deposited Data } \\
\hline \multicolumn{3}{|l|}{ None } \\
\hline \multicolumn{3}{|l|}{ Experimental Models: Cell Lines } \\
\hline HEK293T & ATCC & CRL-3216 \\
\hline \multicolumn{3}{|l|}{ Experimental Models: Organisms/Strains } \\
\hline \multicolumn{3}{|l|}{ Humanized "BLT" mice } \\
\hline \multicolumn{3}{|l|}{ Oligonucleotides } \\
\hline CCL2 Taqman Assay [Hs00234140_m1] & Thermo Fisher & 4331182 \\
\hline IFNB1 Taqman Assay [Hs01077958_s1] & Thermo Fisher & 4331182 \\
\hline CCL20 Taqman Assay [Hs00355476_m1] & Thermo Fisher & 4331182 \\
\hline GAPDH Taqman Assay [Hs02786624_g1] & Thermo Fisher & 4331182 \\
\hline 18S Taqman Assay [Hs03003631_g1] & Thermo Fisher & 4448489 \\
\hline $\begin{array}{l}\text { For Cas9RNP IFI16 Guide } 1 \\
\text { GTACCAACGCTTGAAGACC }\end{array}$ & Dharmacon & Custom \\
\hline $\begin{array}{l}\text { For Cas9RNP IFI16 Guide } 2 \\
\text { GACCAGCCCTATCAAGAAAG }\end{array}$ & Dharmacon & Custom \\
\hline $\begin{array}{l}\text { For Cas9RNP STING Guide } 1 \\
\text { GGTGCCTGATAACCTGAGTA }\end{array}$ & Dharmacon & Custom \\
\hline $\begin{array}{l}\text { For Cas9RNP STING Guide } 2 \\
\text { GCAAGCATCCAAGTGAAGGG }\end{array}$ & Dharmacon & Custom \\
\hline $\begin{array}{l}\text { For Cas9RNP cGAS Guide } 1 \\
\text { TTGAATGCGCAGGCCTTCTT }\end{array}$ & Dharmacon & Custom \\
\hline $\begin{array}{l}\text { For Cas9RNP cGAS Guide } 2 \\
\text { CCGCGATGATATCTCCACGG }\end{array}$ & Dharmacon & Custom \\
\hline $\begin{array}{l}\text { For Alu Forward primer } \\
\text { GCCTCCCAAAGTGCTGGGATTACAG }\end{array}$ & $\begin{array}{l}\text { IDT } \\
\text { PMID: } 12368337\end{array}$ & Custom \\
\hline $\begin{array}{l}\text { For HIV-1 Gag Reverse primer } \\
\text { GCTCTCGCACCCATCTCTCTCC }\end{array}$ & $\begin{array}{l}\text { IDT } \\
\text { PMID: } 12368337\end{array}$ & Custom \\
\hline
\end{tabular}




\begin{tabular}{|c|c|c|}
\hline $\begin{array}{l}\text { For ddPCR Forward primer } \\
\text { TGTGTGCCCGTCTGTTGTGT }\end{array}$ & $\begin{array}{l}\text { IDT } \\
\text { PMID: } 11329067\end{array}$ & Custom \\
\hline $\begin{array}{l}\text { For ddPCR Reverse primer } \\
\text { GAGTCCTGCGTCGAGAGAGC }\end{array}$ & $\begin{array}{l}\text { IDT } \\
\text { PMID: } 11329067\end{array}$ & Custom \\
\hline $\begin{array}{l}\text { Probe for ddPCR (double quenched with Int ZEN) } \\
\text { 6-FAM-CAGTGGCGCCCGAACAGGGA-lowa } \\
\text { Black FQ }\end{array}$ & $\begin{array}{l}\text { IDT } \\
\text { PMID: } 11329067\end{array}$ & Custom \\
\hline \multicolumn{3}{|l|}{ Recombinant DNA } \\
\hline pNL4-3.GFP & PMID: 21111238 & $\mathrm{~N} / \mathrm{A}$ \\
\hline pBaL.GFP & PMID: 28207890 & $\mathrm{~N} / \mathrm{A}$ \\
\hline pNL4-3.Luciferase & PMID: 22291913 & $\mathrm{~N} / \mathrm{A}$ \\
\hline \multicolumn{3}{|l|}{ Software and Algorithms } \\
\hline Prism & $\begin{array}{l}\text { GraphPad Prism } \\
\text { v7\&8 }\end{array}$ & $\begin{array}{l}\text { https://www.graph } \\
\text { pad.com }\end{array}$ \\
\hline FlowJo & FlowJo v10 & $\begin{array}{l}\text { https://www.flowjo. } \\
\text { com/ }\end{array}$ \\
\hline Q-Rex Software & $\begin{array}{l}\text { Q-Rex 1.1.0.4 } \\
\text { (Qiagen) }\end{array}$ & $\begin{array}{l}\text { https://www.qiagen } \\
\text {.com/us/spotlight- } \\
\text { pages/ias/q-rex- } \\
\text { software/ }\end{array}$ \\
\hline QuantaSoft & Bio-Rad & $\begin{array}{l}\text { http://www.bio- } \\
\text { rad.com/en- } \\
\text { us/sku/1864011- } \\
\text { quantasoft- } \\
\text { software- } \\
\text { regulatory- } \\
\text { edition?ID=186401 } \\
1\end{array}$ \\
\hline \multicolumn{3}{|l|}{ Other } \\
\hline None & & \\
\hline
\end{tabular}

